\title{
Summary of Studies of Aging and Environmental Effects on Inconel 617 and Haynes 230
}

Richard N. Wright

September 2006

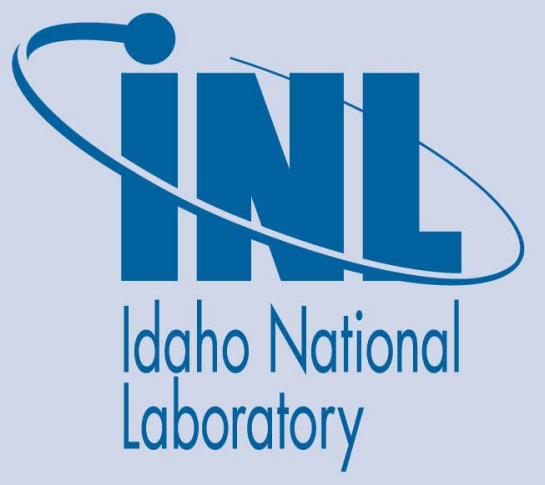

The INL is a U.S. Department of Energy National Laboratory operated by Battelle Energy Alliance 


\title{
Summary of Studies of Aging and Environmental Effects on Inconel 617 and Haynes 230
}

\author{
Richard N. Wright
}

September 2006

Idaho National Laboratory

Idaho Falls, Idaho 83415

Prepared for the U.S. Department of Energy Office of Nuclear Energy Under DOE Idaho Operations Office

Contract DE-AC07-05ID14517 
This page intentionally left blank. 


\section{Signators}

Rafael Soto

Acting NGNP Materials Program Manager

Idaho National Laboratory

Kevan Weaver

Date

NGNP Systems Integration Manager

Idaho National Laboratory

Date 
This page intentionally left blank. 


\section{Executive Summary}

A number of very high temperature helium-cooled reactors have been built and operated for extended periods. The helium coolant in the primary circuit has been found to contain low levels of impurities after steady-state operation that can lead to an environmental degradation of the high temperature alloys used for internals and heat exchangers. Depending on the impurity concentration and the temperature, high temperature alloys can undergo oxidation, carburization, or decarburization. The concentration of $\mathrm{H}_{2} \mathrm{O}$ and $\mathrm{CO}$ is of particular interest because they essentially control the oxygen partial pressure and carbon activity, respectively. The optimum coolant chemistry for long-term stability of high temperature alloys is slightly oxidizing and results in formation of a tenacious and protective $\mathrm{Cr}_{2} \mathrm{O}_{3}$ scale.

The most critical metallic component of the Next Generation Nuclear Plant (NGNP) is the heat exchanger. Inconel 617 is the primary candidate alloy for this application because of its superior creep resistance. The mechanisms of environmental interaction between this alloy and prototype Very High Temperature Reactor (VHTR) helium chemistries have been extensively studied. A modified type of Ellingham diagram that maps the ranges of carbon activity and oxygen partial pressure that result in each of the degradation mechanisms has been developed. The NGNP materials program has designed and built three test loops to extend previous studies on environmental effects of prototype impure helium on Inconel 617 by increasing temperatures and using test coupons that incorporate fusion welds in controlled impurity experiments. In addition, parallel studies have been initiated with a less well-characterized alloy, Haynes 230. The goal of this work is to determine the range of gas chemistries that give rise to stable oxide formation for these alloys at temperatures up to $1000^{\circ} \mathrm{C}$.

Stability of the microstructure and properties of Inconel 617 and Haynes 230 after extended exposure to the elevated temperatures expected in the NGNP heat exchanger are also a potential issue. An aging program has been initiated for these alloys to characterize changes resulting from prolonged high temperature exposure. Furnace aging Inconel 617 in air results in formation of an adherent oxide scale and a carbide depleted zone beneath the oxide. There is some grain growth with increasing time at elevated temperature and the distribution of grain sizes becomes broader. There are modest changes in the mechanical properties for the aging conditions that have been examined. Decreased yield strength with increasing time at elevated temperature is consistent with the increasing grain size. Aging under load results in notable redistribution of carbides to some of the grain boundaries that experience tensile loading for some temperatures and applied stress values. Details of this phenomenon are being examined in detail. 
This page intentionally left blank. 


\section{Contents}

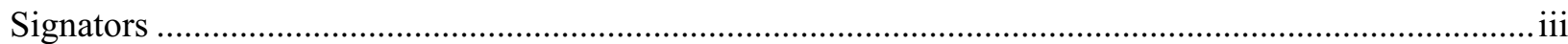

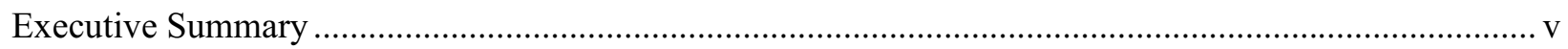

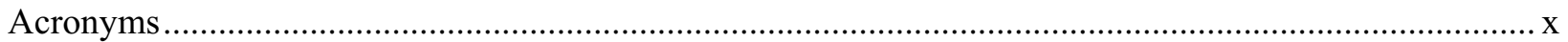

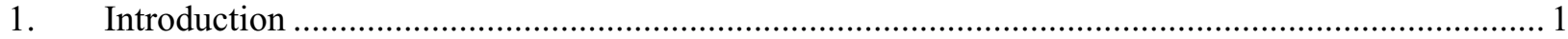

2. Impurities In Helium-Cooled High Temperature Gas-Cooled Reactors ....................................... 3

3. Environmental Interactions Between VHTR Helium and High Temperature Alloys ....................... 4

4. Current Testing Programs for VHTR Environmental Interactions................................................ 6

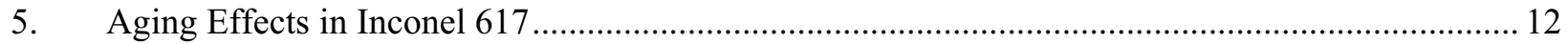

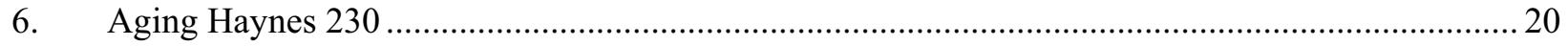

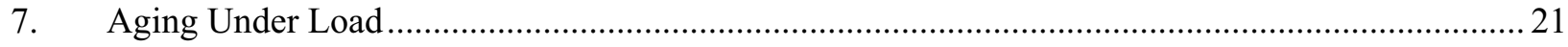

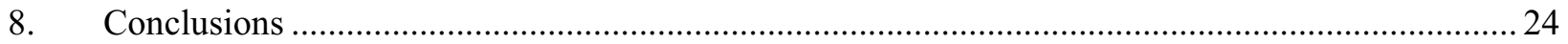

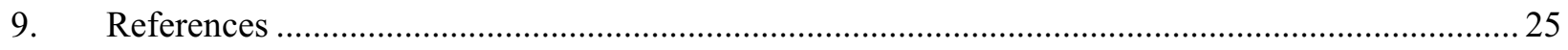




\section{Figures}

Figure 1. An artist's conception of a very high temperature gas cooled reactor and associated hydrogen production. 1

Figure 2. Zone III in the Ellingham stability diagram is preferred for optimal chromia layer protection against corrosion. 5

Figure 3. Schematic of one of the French corrosion test loops............................................................ 7

Figure 4. Schematic of the INL low velocity controlled chemistry helium materials test system............... 8

Figure 5. Details of the retort for exposure of test coupons.................................................................. 9

Figure 6. Detail of the arrangement of coupons in the NIL retort shown with the furnace open............... 9

Figure 7. Photograph of the low velocity controlled impurity chemistry test loop at ORNL.................... 10

Figure 8. This plot shows the loop water vapor content being controlled to a set point of $4 \mathrm{ppm}$ for over 50 hours. At approximately 57 hours, the set point was reduced to a value of $2 \mathrm{ppm}$. The duty cycle for the solenoid control valve immediately dropped to less than $0.5 \%$ to bring the water vapor content to $2 \mathrm{ppm}$.

Figure 9. Montage of optical micrographs showing the grain size and carbide distribution in as-received Inconel 617 plate. The dolling direction (RD), short transverse (ST) and long transverse (LT) directions are noted.

Figure 10. Optical micrographs of Alloy 617 aged in air for (a) 30 and (b) 3000 hours at $1000^{\circ}$. 13

Figure 11. Alloy 617 exposed in air for 1000 hours at $1000^{\circ} \mathrm{C}$. The thickness of oxide, extent of internal oxidation and depth of carbide depletion are shown as regions $\mathrm{A}, \mathrm{B}$, and $\mathrm{C}$, respectively. .......... 14

Figure 12. Depth of carbide depleted zone as a function of time in a $20 \mathrm{~mm}$ thick Alloy 617 plate exposed in air at $1000^{\circ} \mathrm{C}$

Figure 13. Backscattered electron images of $12.5 \mathrm{~mm}$ thick Inconel 617 plate aged in air for 1000 hours. 15

Figure 14. Secondary electron images of $12.5 \mathrm{~mm}$ Inconel 617 plate aged for 1000 hours in air. 16

Figure 15 a-e. Grain size distributions for Inconel 617 (a) in the as-received condition and (b) and (c) aged at $800^{\circ} \mathrm{C}$ for 1000 and 3000 hours and (d) and (e) aged at $1000^{\circ} \mathrm{C}$ for 1000 and 3000 hours. 17

Figure 16. Cumulative grain size for $12.5 \mathrm{~mm}$ thick Inconel 617 plate aged at (a) $800^{\circ} \mathrm{C}$ and (b) $1000^{\circ} \mathrm{C} .18$

Figure 17. Orientation of the Charpy impact bars with respect to the Inconel 617 plate. 20

Figure 18. Aging will continue with similar characterization as the Inconel 617. 20

Figure 19. Image of sample TML-IN617-01, small grain area. 22 
Figure 20. Images of the same area generated from image quality and EDS information gathered during OIM scans.

Figure 21. Images of TML-IN617-01 from areas of small grain size (left column) and large grain size (right column).

\section{Tables}

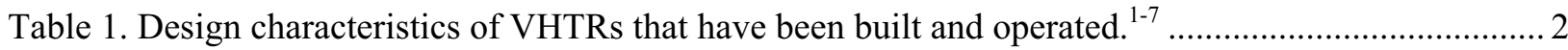

Table 2. Compositions of potential high-temperature alloys for NGNP; compositions in $\mathrm{wt} \%{ }^{14-17} \ldots \ldots \ldots . .2$

Table 3. Impurities reported in the helium coolant during steady-state operation of VHTRs (in ppm). ${ }^{1,2,18,19}$

Table 4. Model impurity chemistries used in environmental testing programs (compositions in ppm). HHT, PNP were used for German nuclear process heat projects. AGCNR was a German VHTR, and JAERI B composition was extensively studied in development of the HTTR. ${ }^{20-30}$................. 4

Table 5. Tensile properties of Inconel 617 aged at $1000^{\circ} \mathrm{C}$ in air. Mechanical property characterization was done in air at room temperature, 800 and $1000^{\circ} \mathrm{C}$.

Table 6. Room temperature Charpy impact values for Inconel 617 aged at $1000^{\circ} \mathrm{C}$

Table 7: Summary of Creep Conditions 


\section{Acronyms}

AGCNR Advanced Gas-Cooled Nuclear Reactor

ASTM American Society for Testing and Materials

AVR Arbeitsgemeinschaft Versuchsreaktor (Germany)

EBSD Electron Backscatter Detector

EDS Energy Dispersive Spectroscopy

HHT High-temperature Helium Turbine System

HPS Helium Purification System

HTTR High-Temperature Test Reactor (Japan)

INERI International Nuclear Energy Research Initiative

INL Idaho National Laboratory

JAERI Japanese Atomic Energy Research Institute

NGNP Next Generation Nuclear Plant

OIM Orientation Imaging Microscopy

ORNL Oak Ridge National Laboratory

PBMR Pebble Bed Modular Reactor

PNP Prototype Nuclear Process Heat

ppm parts per million

THTR Thorium High-Temperature Reactor (Germany)

VHTR Very High Temperature Reactor 


\section{Introduction}

The Next Generation Nuclear Plant (NGNP) is being developed to produce hydrogen as well as electricity. Conceptual designs call for a gas-cooled reactor with an outlet temperature greater than the $850^{\circ} \mathrm{C}$ required to efficiently operate the hydrogen generation plant, with a maximum of $950^{\circ} \mathrm{C}$. While the design concepts are not yet final, it is highly probable that helium will be the working fluid in the reactor. The primary material in the core will be graphite, and the prime candidates for metallic internal components are the nickel-based alloys Inconel 617 or Alloy 230. An artist's representation of one concept for the reactor and power conversion vessel and the associated hydrogen generation plants is shown in Figure 1. In this representation a heat exchanger will carry most of the reactor thermal output to a secondary circuit that will power a turbine for electricity generation. An additional heat exchanger will take approximately $10 \%$ of the thermal energy of the reactor and divert it as process heat to the hydrogen production plant.

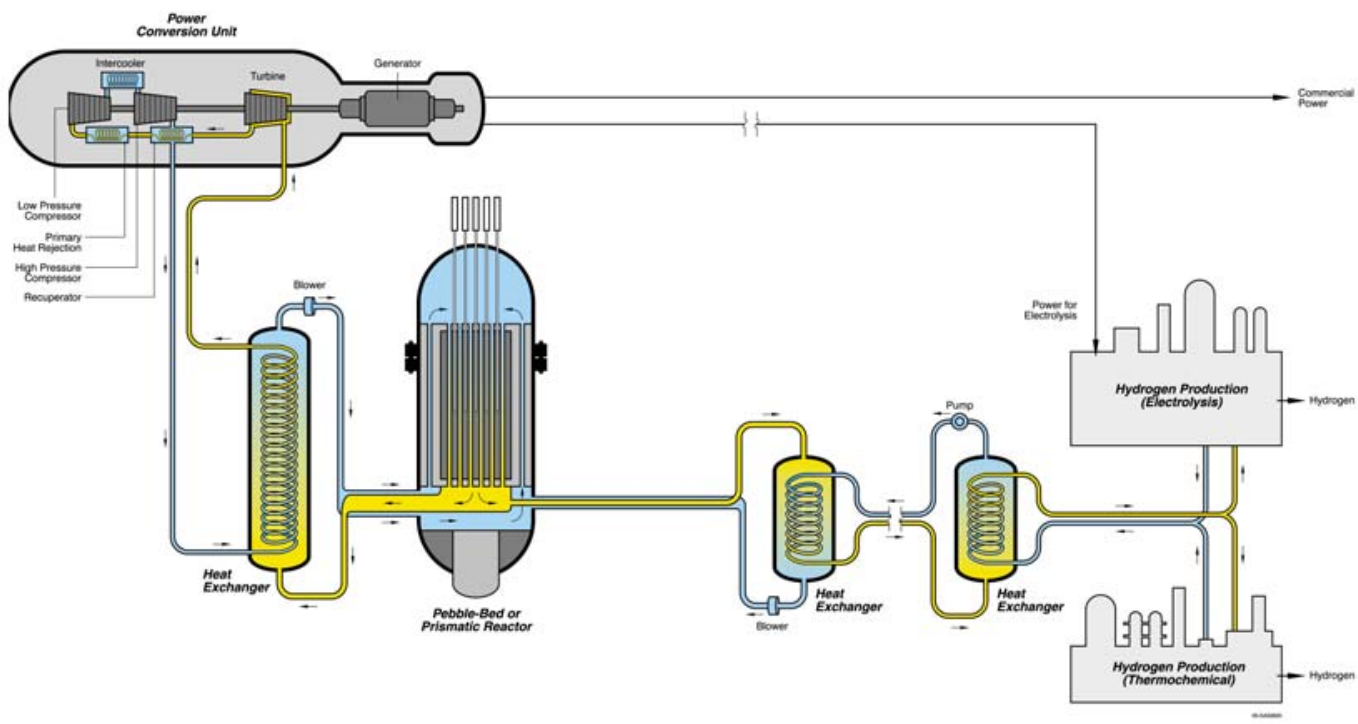

Figure 1. An artist's conception of a very high temperature gas cooled reactor and associated hydrogen production.

The most critical metallic component in the NGNP system is the heat exchanger. This heat exchanger will operate at the reactor outlet temperature of up to $950^{\circ} \mathrm{C}$. In addition, the reactor system is intended to have a license period of 60 years. The combination of very high temperature operation and long duration of service restricts material choices for the heat exchanger to a small number of coarsegrained solid-solution strengthened alloys that provide stability and creep resistance and have high chromium content for environmental resistance.

Very early in the development of nuclear power for electricity generation or process heat, the concept of an inert gas-cooled, high temperature reactor was explored. The Peach Bottom reactor in the Unites States and the European Dragon project were among the first to seriously address the technical issues associated with high temperature environmental interaction between the cooling gas and metallic components. ${ }^{1-3}$ Proposals for a Very High Temperature Reactor (VHTR) with outlet temperature of $1000^{\circ} \mathrm{C}$ or above were developed by the late 1970 's. The Arbeitsgemeinschaft Versuchsreaktor (AVR) was the first experimental pebble bed reactor. A commercial demonstration scale pebble bed, the Thorium 
High-Temperature Reactor (THTR), was developed based on AVR experience. A summary of important design characteristics for gas-cooled VHTRs that have been operated to date are given in Table $1 .^{1-7}$ The High-Temperature Test Reactor (HTTR) in Japan is the only one of the reactors listed in the table that is still in operation.

Table 1. Design characteristics of VHTRs that have been built and operated. ${ }^{1-7}$

\begin{tabular}{lcccccc}
\hline & Dragon & AVR & $\begin{array}{c}\text { Peach } \\
\text { Bottom }\end{array}$ & $\begin{array}{c}\text { Ft. St. } \\
\text { Vrain }\end{array}$ & $\begin{array}{c}\text { THTR- } \\
\text { 300 }\end{array}$ & HTTR \\
\hline Country of Origin & OECD/Britain & Germany & U.S. & U.S. & Germany & Japan \\
Thermal Power MWt & 21.5 & 46 & 115 & 842 & 750 & 30 \\
Net Electric Power MWe & - & 13 & 40 & 330 & 300 & 10 \\
$\begin{array}{l}\text { Maximum Core Outlet Temp } \\
{ }^{\circ} \mathrm{C}\end{array}$ & 750 & 950 & 725 & 775 & 750 & 950 \\
Helium Pressure MPa & 2.0 & 1.1 & 2.25 & 4.8 & 3.9 & 4 \\
Steam Temp ${ }^{\circ} \mathrm{C}$ & - & 505 & 538 & 538 & 530 & \\
Reactor Type & Sleeve & Pebble & Sleeve & Block & Pebble & Prism \\
Vessel Material & Steel & Steel & Steel & PCRV & PCRV & Steel \\
Date of Operation & $1964-1975$ & 1966 & 1967 & $1979-1989$ & 1985 & 1997 \\
\hline
\end{tabular}

a. Pre-stressed concrete reactor vessel.

The cooling gas of choice for high temperature gas reactors is helium. Although the helium is nominally pure, there are, inevitably, impurities at the parts per million by volume (ppm) levels in the coolant in operating high temperature reactors. Several reviews of the behavior of metallic alloys for control rods, core internals, and heat exchangers in the reactor helium environment are available. ${ }^{8-13}$ The desire for higher temperature operation resulted in evolution of the materials under consideration, from stainless steels to iron-based high temperature alloys to nickel-based alloys. An extensive German program in the 1980's carried out exhaustive studies of the corrosion behavior of the iron-based alloy $800 \mathrm{H}$ for control rods and nickel-based Inconel 617 for structural applications. ${ }^{8-12}$ The Japanese HTTR program extensively studied Haynes Alloy X and developed a variation known as XR with improved properties for some applications, while retaining $800 \mathrm{H}$ for the control rods. ${ }^{14}$ Compositions of these candidate alloys are given in Table $2 .{ }^{14-17}$ Based on creep resistance above $850^{\circ} \mathrm{C}$, the leading candidate alloys for NGNP are Inconel 617 and Haynes 230.

Table 2. Compositions of potential high-temperature alloys for NGNP; compositions in wt $\% .{ }^{14-17}$

\begin{tabular}{|c|c|c|c|c|c|c|c|c|c|c|c|}
\hline Alloy & $\mathbf{N i}$ & $\mathbf{F e}$ & $\mathrm{Cr}$ & Co & Mo & Al & $\mathbf{W}$ & $\mathbf{T i}$ & $\mathrm{C}$ & $\mathbf{S i}$ & Mn \\
\hline Inconel 617 & 44.5 & 3 & $20-24$ & $10-15$ & $\begin{array}{l}8- \\
10\end{array}$ & $0.8-1.5$ & & 0.6 & $\begin{array}{c}0.05- \\
0.15\end{array}$ & 1 & 1 \\
\hline Alloy 230 & Bal & 3 & $20-24$ & 5 & $1-3$ & $0.2-0.5$ & $\begin{array}{l}13- \\
15\end{array}$ & & $\begin{array}{c}0.05- \\
0.15\end{array}$ & $.25-.75$ & $\begin{array}{c}0.3- \\
1\end{array}$ \\
\hline Alloy $800 \mathrm{H}$ & $30-35$ & 39.5 & $19-23$ & & & $\begin{array}{c}0.15- \\
0.6\end{array}$ & & $0.15-0.6$ & $0.05-0.1$ & & \\
\hline Alloy XR & $\mathrm{Bal}$ & 20 & 23 & 1 & 10 & 0.1 & 1 & 0.03 & 0.15 & 0.5 & 1 \\
\hline
\end{tabular}


A common characteristic of the alloys that have been put in service in high temperature gas-cooled reactors is that they rely primarily on the formation of a tenacious chromium scale for long-term protection from environmental interaction with the gas cooling environment. ${ }^{8-10,13}$ The alloys are also primarily solid solution strengthened with carbides on the grain boundaries to stabilize the microstructure and enhance the creep resistance. Sustaining such a protective surface requires sufficient oxygen partial pressure. While helium is normally considered to be inert, experience has shown that the helium in reactors has a number of impurities at low but significant levels that affect the performance of materials depending on the chemistry of the particular alloy, the concentration of impurities, and the temperature the alloy can be oxidized, carburized, or decarburized.

A test program to investigate the behavior of high temperature alloys in low velocity flowing helium with controlled levels of impurities at temperatures up to $1000^{\circ} \mathrm{C}$ is active within the NGNP Materials Program. This report will describe the status of the test loops and features of the planned test program.

In addition to testing in controlled chemistry helium, the expected long service life of the NGNP heat exchangers has raised potential issues with the stability of the microstructure and properties of alloys during extended aging. The results of an ongoing program to study the microstructure and mechanical properties of Inconel 617 and Haynes 230 aged in air at temperatures up to $1000^{\circ} \mathrm{C}$ are also summarized in this report. The scoping studies described here on aging effects have been carried out on two commercial heats of Inconel 617 and one heat of Haynes 230 and are being conducted in support of the effort to qualify one or more high temperature alloys in the ASME Code for NGNP service, for this effort the appropriate atmosphere is laboratory air.

\section{Impurities In Helium-Cooled High Temperature Gas-Cooled Reactors}

All of the high temperature reactor systems operated to date have had extensive gas clean-up systems associated with the helium coolant flow. These systems are intended to keep the total impurity levels in the helium below typically $10 \mathrm{ppm}$. Particularly in the early reactors, where the fuel was either not intended to contain the fission products or was ineffective in this function, the clean up systems were also intended to capture radionuclides. ${ }^{2,3}$ Capture of tritium that is produced (at least in part) by transmutation of lithium impurities in the graphite remains an important function of the clean up system. In the AVR and THTR reactors, active control was maintained on the $\mathrm{H}_{2} \mathrm{O}$ and $\mathrm{CO}$ concentrations to reduce oxidation of the graphite reflectors, and the other impurities were routinely found to reach acceptable steady-state levels without active control. ${ }^{4-7,18,19}$ It has been noted that the clean-up systems may play a secondary role in maintaining gas chemistry, with the massive amount of graphite at high temperature present in all of the reactor designs playing a dominant role. ${ }^{2}$

Molecular sieves are effective in capture of most of the gaseous impurities; however, they have difficulty capturing $\mathrm{H}_{2}$ and $\mathrm{CO}$. To resolve this problem, the gas stream is passed over a bed of $\mathrm{CuO}$ that oxidizes the $\mathrm{H}_{2}$ to $\mathrm{H}_{2} \mathrm{O}$ and $\mathrm{CO}$ to $\mathrm{CO}_{2}$ upstream of the molecular sieve where these gases are effectively removed. The Peach Bottom plant attempted the use of heated Ti getters for hydrogen and tritium; however, these were not effective and oxidation of the $\mathrm{H}_{2}$ prior to removal is now accepted practice. ${ }^{1}$ In a typical plant, up to about $20 \%$ of the gas stream is diverted to the clean up system each hour.

Table 3 shows the impurity levels reported for steady-state operation for several of the VHTRs. ${ }^{1,2,18,19}$ As shown in the table, at steady-state, all of the reactors for which operating data are available had similar levels of impurities. Some caution should be exercised when comparing the data for different plants, since, in some cases, there are varying values reported in different publications for the 
same plant. This may be associated with conversion from partial pressure of impurities (the preferred units for corrosion studies) to ppm by volume (the typical units used for comparison of one plant to another). Several plants have undergone extensive post-mortem analysis of the core internals and heat exchangers. ${ }^{1,2}$ There are reports of some oxidation and at least one report of massive deposition of carbon on the internals, as discussed in more detail below; however, there have been no problems with failure of components on the primary side associated with environmental effects.

Table 3. Impurities reported in the helium coolant during steady-state operation of VHTRs (in ppm). ${ }^{1,2,18,19}$

\begin{tabular}{lccccccc}
\hline & $\mathbf{H}_{\mathbf{2}} \mathbf{O}$ & $\mathbf{H}_{\mathbf{2}}$ & $\mathbf{C O}$ & $\mathbf{C O}_{\mathbf{2}}$ & $\mathbf{C H}_{\mathbf{4}}$ & $\mathbf{O}_{\mathbf{2}}$ & $\mathbf{N}_{\mathbf{2}}$ \\
\hline Dragon & 0.1 & 0.1 & 0.05 & 0.02 & 0.1 & 0.1 & 0.05 \\
Peach Bottom & 0.5 & 10 & 0.5 & $<0.05$ & 1.0 & - & 0.5 \\
Fort St. Vrain & 1 & 7 & 3 & 1 & 0.1 & - & - \\
AVR & 0.15 & 9 & 45 & 0.25 & 1 & & 22 \\
THTR & $<0.01$ & 0.8 & 0.4 & 0.2 & 0.1 & & 0.1 \\
\hline
\end{tabular}

\section{Environmental Interactions Between VHTR Helium and High Temperature Alloys}

There has been a vast amount of experimental studies and modeling of the effect of VHTR helium on the high temperature alloys listed in Table $2 .^{8,9,11-14,20-30}$ Depending on the specific proposed application, different model chemistries have been developed, and the testing has focused on these. Several of the model impurity chemistries are shown in Table $6 .{ }^{20-30}$ Comparing the values in Table 6 with actual operating experience suggest that the model chemistries tend to have higher impurity levels of some species than those found in operating reactors. This is notable for $\mathrm{H}_{2}$ in particular. It is not clear why these particular values were chosen; however, it can be noted that several of the proposed applications were for process heat for coal gasification, and there was concern that hydrogen would diffuse from the process plant into the primary coolant circuit. ${ }^{20}$ Note that $\mathrm{N}_{2}$, at concentrations similar to those listed in Table 4 has never been found to contribute significantly to environmental interactions with nickel-based alloys. ${ }^{25-26}$

Table 4. Model impurity chemistries used in environmental testing programs (compositions in ppm). HHT, PNP were used for German nuclear process heat projects. AGCNR was a German VHTR, and JAERI B composition was extensively studied in development of the HTTR. ${ }^{20-30}$

\begin{tabular}{cccccccc}
\hline & $\mathbf{H}_{\mathbf{2}} \mathbf{O}$ & $\mathbf{H}_{\mathbf{2}}$ & $\mathbf{C O}$ & $\mathbf{C O}_{\mathbf{2}}$ & $\mathbf{C H}_{\mathbf{4}}$ & $\mathbf{O}_{\mathbf{2}}$ & $\mathbf{N}_{\mathbf{2}}$ \\
\hline HHT & 0.75 & 250 & 20 & & 25 & 5 \\
PNP & 0.75 & 250 & 7 & & 10 & $<2.5$ \\
AGCNR & 1 & 200 & 20 & 0.1 & 10 & $<2.5$ \\
JAERI B & 0.5 & 100 & 50 & 1 & 2.5 & & $<2.5$ \\
\hline
\end{tabular}

Interplay between the alloy surface, temperature, and gas composition determines whether corrosive oxidation, carburization, or decarburization occurs. The corrosion mechanisms of particular significance to mechanical stability are carburization and decarburization. Carburization is associated with low temperature embrittlement, and decarburization is linked to reduced creep rupture strength. 
Ideally, a continuous self-healing, impermeable passivating oxide layer is needed to establish the most corrosion-resistant alloy. In the case of Inconel 617, its chromia layer $\left(\mathrm{Cr}_{2} \mathrm{O}_{3}\right)$ is the most important barrier from the effects of corrosive reactor gases.

Of the existing alloys, a nickel chromium alloy Inconel 617 is the leading candidate for use in the NGNP heat exchangers because it has the highest creep strength of the solid solution alloys under consideration for temperatures above $850^{\circ} \mathrm{C}$. Evaluation of this alloy for VHTRs began in the early 1980 's with the most comprehensive work done by Quadakkers, Christ and Graham. ${ }^{23-30}$ The newer alloy Haynes 230 is under consideration as an alternative to Inconel 617 because it has equivalent creep properties and may suffer from less internal oxidation.

Based upon the work of Quadakkers and others, assessments of Inconel 617 stability at various gas concentrations and temperatures can be displayed graphically. Quadakkers utilized a modified Ellingham diagram, Figure 2, to display results of the nickel-chromium alloy's stability calculations. ${ }^{23-28,31}$ Five conditions are represented within the diagram: I-strongly reducing, II-highly oxidizing, III-stable external oxide with stable internal carbides, IV-strongly carburizing internally and externally, and, lastly, IVastrong external carburization with stable oxide layer. Zone III was determined to be the area of highest stability, an environment oxidizing yet slightly carburizing. A heat exchanger operating at temperatures of $900^{\circ} \mathrm{C}$ and assuming AGCNR gas composition Inconel 617 would be in zone III, for example.

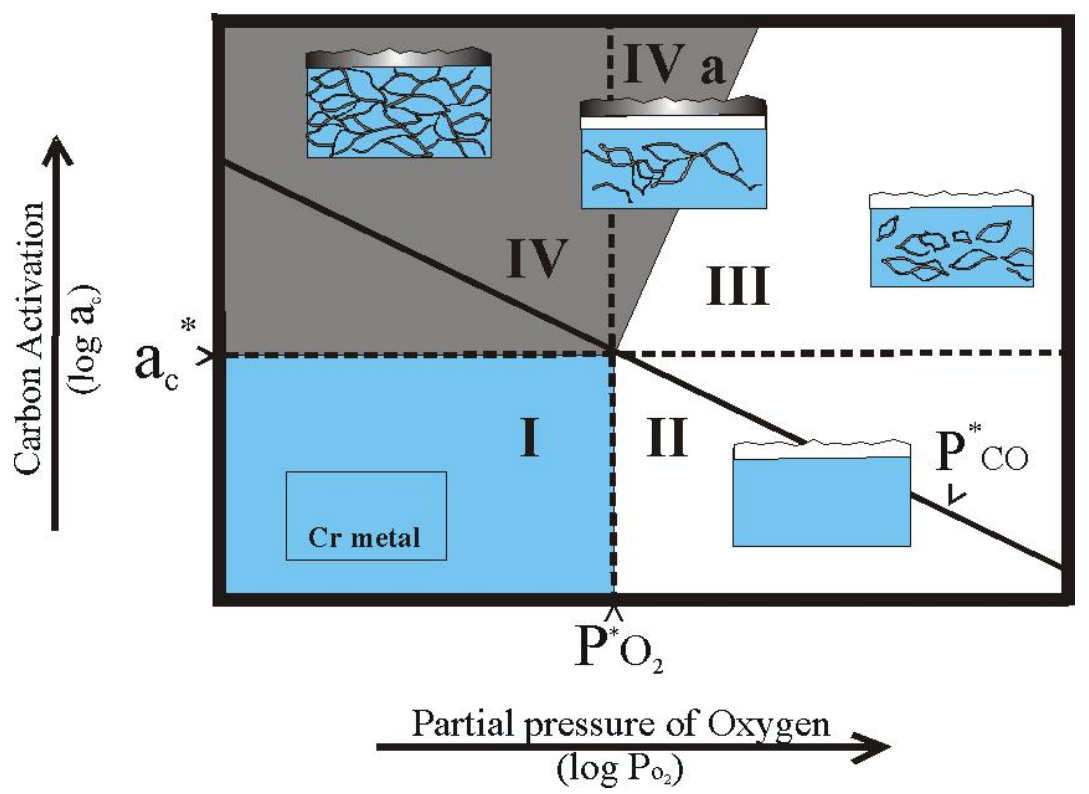

Figure 2. Zone III in the Ellingham stability diagram is preferred for optimal chromia layer protection against corrosion.

The modified Ellingham diagram describing alloy stability was based on the most relevant species involved in the corrosion process, namely chromium. Identifying which form $-\mathrm{Cr}_{2} \mathrm{O}_{3}$ chromium carbide, or chromium metal - is most stable in a particular environment will determine the ultimate fate of the alloy. ${ }^{32}$ It is important to note that the gas chemistries found in operating reactors and used in the previous test programs are not in thermodynamic equilibrium. A steady-state gas composition is reached at any temperature based on kinetic considerations. As will be shown below, the concentrations of $\mathrm{H}_{2} \mathrm{O}$ and $\mathrm{CO}$ largely determine the partial pressure of oxygen and activity of carbon, respectively. The important features of the diagram are critical carbon activation $(\mathrm{ac} *)$, critical partial pressure of oxygen $\left(\mathrm{P}^{*} \mathrm{O}_{2}\right)$, and the critical partial pressure of carbon monoxide $\left(\mathrm{P}^{*} \mathrm{CO}\right)$. These parameters are calculated from the following thermodynamic reactions: 


$$
\begin{array}{lll}
\mathrm{a}_{\mathrm{c}}^{*} & 23 \mathrm{Cr}+6 \mathrm{C}=\mathrm{Cr}_{23} \mathrm{C}_{6} & \text { metal-carbide equilibrium activity } \\
\mathrm{P}^{*} & \mathrm{O}_{2} \mathrm{Cr}_{2} \mathrm{O}_{3}=2 \mathrm{Cr}+1.5 \mathrm{O}_{2} & \text { disassociation pressure of chromia } \\
\mathrm{P} * & \mathrm{CO} 3 \mathrm{CO}+2 \mathrm{Cr}=\mathrm{Cr}_{2} \mathrm{O}_{3}+3 \mathrm{C} & \mathrm{CO} \text { pressure for this equilibrium }
\end{array}
$$

The measured steady-state conditions (AGCNR gas composition) determine where the alloy sits within the Ellingham diagram; hence, the steady-state carbon activity $\left(\mathrm{a}_{\mathrm{c}}{ }^{\mathrm{ss}}\right)$ and the steady-state oxygen pressure $\left(\mathrm{PO}_{2}{ }^{\mathrm{ss}}\right)$ are calculated with the following equations:

$$
\begin{array}{lll}
\mathrm{a}_{\mathrm{c}}{ }^{\mathrm{ss}} & \mathrm{CO}=\mathrm{C}+0.5 \mathrm{O}_{2} & \mathrm{a}_{\mathrm{c}}^{\mathrm{ss}}=\mathrm{K} \cdot\left(\mathrm{P}_{\mathrm{CO}}^{\mathrm{ss}} / \mathrm{P}_{\mathrm{O} 2}{ }^{\mathrm{ss}} 1 / 2\right) \\
\mathrm{PO}_{2}{ }^{\mathrm{ss}} & \mathrm{H}_{2} \mathrm{O}=\mathrm{H}_{2}+[\mathrm{O}] & \mathrm{PO}_{2}{ }^{\mathrm{ss}}=\left(\mathrm{K}^{\mathrm{P}} \cdot \mathrm{PH}_{2} \mathrm{O} / \mathrm{PH}_{2}\right)^{2} \cdot\left(1-\left(\mathrm{PCH}_{4} / \mathrm{PH}_{2} \mathrm{O}\right) \cdot 1 / 100\right)
\end{array}
$$

A local chromium activity of 0.75 is associated with the following reaction: ${ }^{25,26}$

$$
2 \mathrm{Cr}_{2} \mathrm{O}_{3}+\mathrm{Cr}_{23} \mathrm{C}_{6}=6 \mathrm{CO}+27 \mathrm{Cr} \text {. }
$$

The onset of this event occurs at a particular temperature, TA, when the CO concentration is no longer sufficient to drive the reaction from right to left. It results in eventual total loss of either chromium oxide or carbide, depending on concentration, then complete carburization or decarburization of the alloy, depending on the gas composition. This degradation mechanism is not considered in the stability diagrams developed using the approach of Quadakkers; however, it has been discussed extensively by Graham and Christ. ${ }^{25,26,28-30}$ Important variables are temperature TA $\left(\sim 980^{\circ} \mathrm{C}\right.$ for Inconel 617 with the AGCNR chemistry) and measured CO pressure verses $\mathrm{P} * \mathrm{CO}$. At the temperature TA, the reaction will go to completion, and, as a result, this temperature represents a maximum use temperature for the particular alloy for a given gas composition.

Another shortcoming of the stability diagram approach presented above is that it does not account for the fact that $\mathrm{Cr}_{2} \mathrm{O}_{3}$ becomes volatile at a temperature above about $950{ }^{\circ} \mathrm{C} .{ }^{33}$ There may be sufficient oxygen partial pressure to form the oxide as predicted from the modified Ellingham diagram; however, it will not be protective because of the very high vapor pressure of the oxide. Most laboratory studies have been at very low flow rates to more closely approach thermodynamic equilibrium for fundamental studies of corrosion mechanisms. It has been noted that these conditions may not be representative of reactor systems, where very high gas velocities are likely, e.g., 50 to $75 \mathrm{~ms}^{-1}$ at the outlet of the NGNP. ${ }^{25,26}$ With very low levels of impurities, this increases the possibility that impurities will be depleted during the experiments and may give rise to anomalously low values for $\mathrm{Cr}_{2} \mathrm{O}_{3}$ vaporization in test systems compared to reactor operation. ${ }^{22,25,26,28-30}$

\section{Current Testing Programs for VHTR Environmental Interactions}

There is currently a project in the NGNP materials program to investigate environmental effects on the microstructure of Inconel 617 and Haynes 230 in plate form as well as fusion welds in both materials. This project is being carried out jointly between Idaho National Laboratory (INL) and Oak Ridge National Laboratory (ORNL). The behavior of common lots of material is being characterized in helium with impurities at the AGCNR model chemistry values shown in Table 4. The main focus of the investigation is determining the influence of changes in the $\mathrm{H}_{2} \mathrm{O}$ and $\mathrm{CO}$ concentrations on the mechanism of corrosion at temperatures up to $1000^{\circ} \mathrm{C}$. A computer program has been developed aimed at predicting whether the interaction between the alloy and a particular chemistry for a given temperature is oxidizing, carburizing, or decarburizing based on Quadakker's approach. ${ }^{23,24}$ The approach being taken in 
this program is to predict behavior for chemistries within different regions in the stability diagram and then carry out well-controlled experiments to characterize the actual behavior. Despite the extensive programs examining environmental interactions under similar conditions in the past, there is sufficient uncertainty in some of the parameters that go into the model, particularly the chromium activity, thermochemistry of chromium carbides, and the influence of minor alloying elements, to create uncertainty about the boundaries between different degradation mechanisms.

There is a parallel effort within the Generation IV program, particularly in France. An International Nuclear Energy Research Initiative (INERI) has been established between the U.S. program and the French program as a formal mechanism to exchange information. The focus and approach of the two programs is somewhat different so that they are largely complementary rather than duplicative. A schematic of one of the test systems used in the French corrosion program is shown in Figure 3 below. This system uses a single test coupon and makes dynamic measurements of weight gain or loss. Gas flow in the system is once through and uses premixed gas compositions. In contrast to the loops being operated in the U.S., the French systems tend to use due point measurements for the concentration of $\mathrm{H}_{2} \mathrm{O}$. While these systems are somewhat more complex than the solid-state devices used in the U.S., they are capable of measuring water concentrations at values much less than one ppm. The French program has been carrying out experimental work for several years and preliminary results have been published. ${ }^{34-36}$

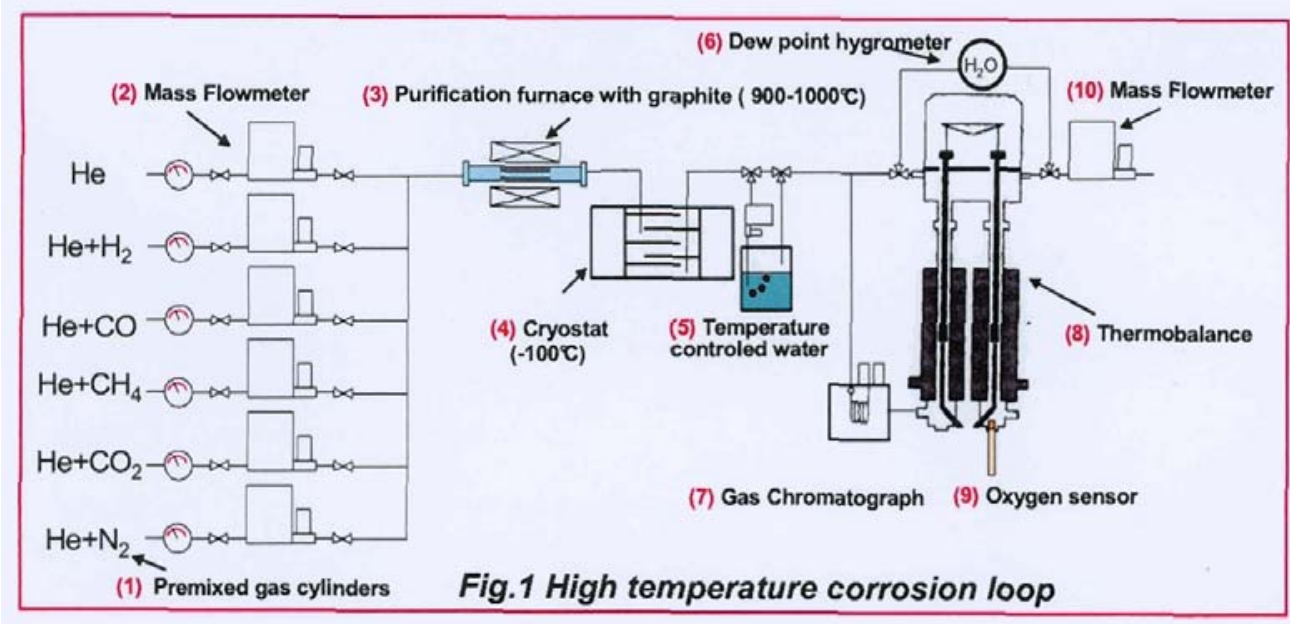

Figure 3. Schematic of one of the French corrosion test loops.

The NGNP experimental environmental effects project has concentrated on establishing test loops at INL and ORNL. A closed-circuit, low flow velocity test loop has been designed and assembled at INL. This loop has the ability to expose coupons and mechanical test specimens in a controlled impurity atmosphere at high temperature for long periods. The test systems at ORNL have been designed such that the gas chemistry is controlled by bleeding off a portion of the test atmosphere and refreshing to the desired chemistry with controlled additions of gas. While the INL system is designed so that it can operate in this mode, it is also designed with the potential to continuously getter excess impurities and add necessary trace impurities based on mass spectroscopy measurements in a closed loop system.

A schematic of the components of the INL test loop is shown in Figure 4. The schematic shows that the system has a vent system that will only be used in the so-called "bleed and feed" mode of operation. The system can be evacuated to a pressure of $10^{-6}$ torr in the specimen chamber using a turbomolecular pump. All of the tubing for the system is stainless steel and can be heated during evacuation to 
help remove adsorbed impurities. There is a metal bellows pump in the loop capable of $40 \mathrm{l} / \mathrm{m}$ flow; the total system volume is approximately 20 liters.

The test section consists of concentric quartz tubes inside the furnace section where cool gas moves down through the annulus and returns up past specimens that will be suspended on a central rod. The hot zone of the retort is approximately $0.75 \mathrm{~m}$ in length and is designed to operate up to $1000^{\circ} \mathrm{C}$. The quartz tubes are sealed to the system using an o-ring assembly that allows tubes to be disassembled to insert and retrieve specimens and to replace quartz tubes as necessary. Details of the retort and fittings are shown in Figure 5. Although provision has been made to water cool the aluminum fittings that hold the o-ring seal assembly for the quartz tubes, experiments with flowing helium up to $1000^{\circ} \mathrm{C}$ have indicated that it will probably not be necessary. Figure 6 is a photograph showing in detail the method of suspending test coupons in the retort of the INL loop.

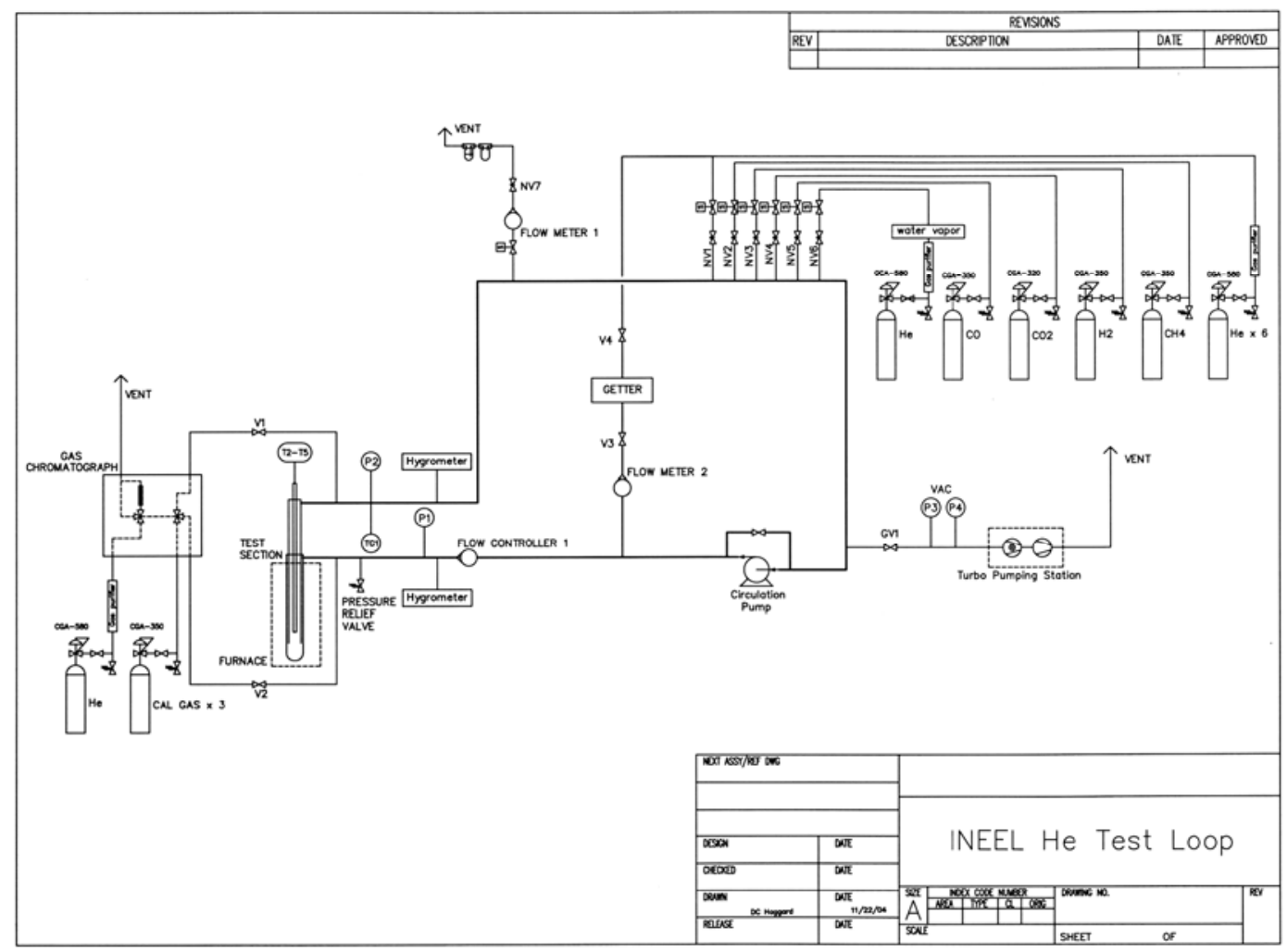

Figure 4. Schematic of the INL low velocity controlled chemistry helium materials test system. 


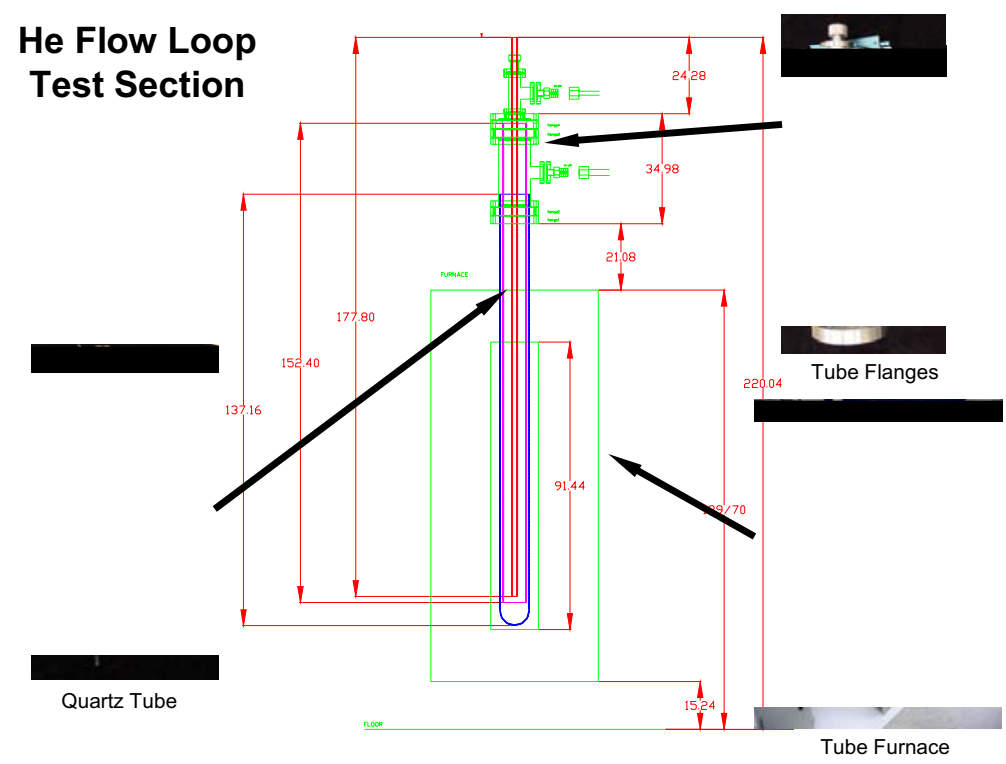

Figure 5. Details of the retort for exposure of test coupons.

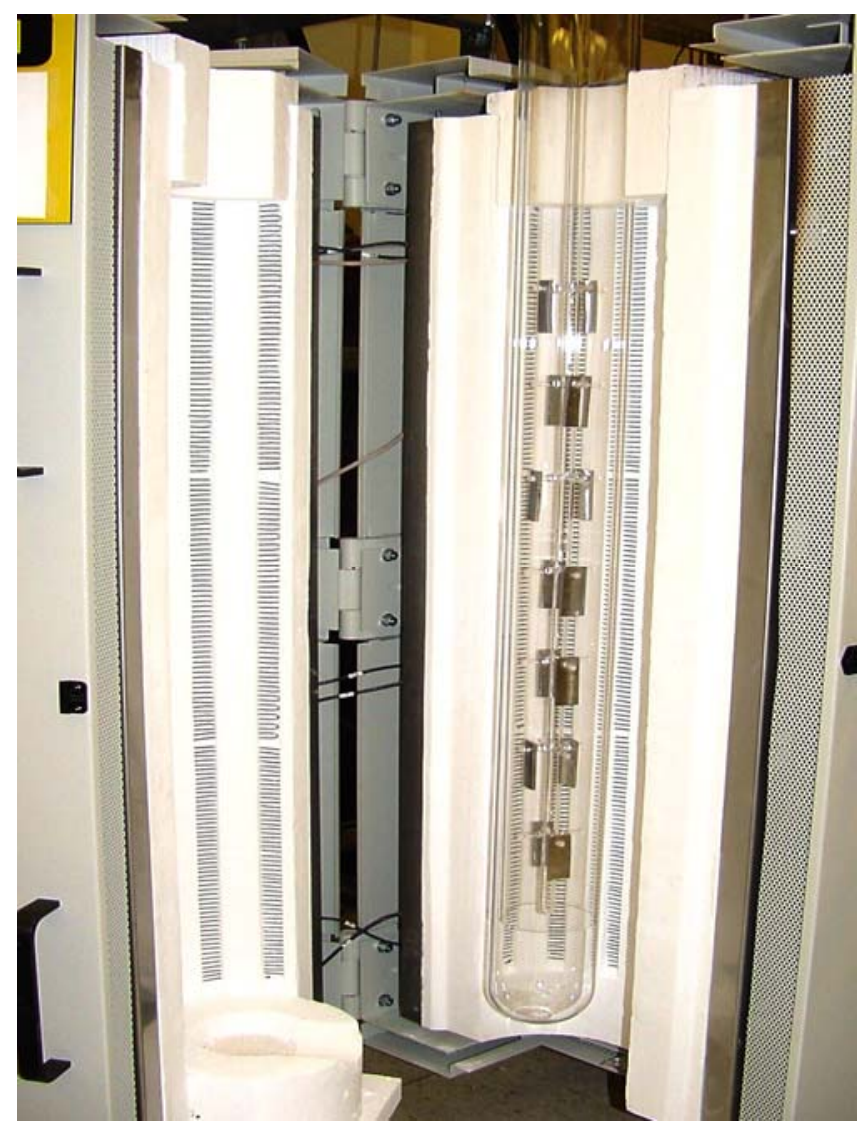

Figure 6. Detail of the arrangement of coupons in the NIL retort shown with the furnace open..

Gas composition is measured going into the retort and upon exit from the hot zone. Water vapor content is measured using solid-state hygrometers. The content of the other impurities is measured using a 
gas chromatograph with a pulsed ionization source. All of the gas compositions will be measured to one part per million or less. As shown in Figure 4, all of the impurities are added to the system as individual gases, rather than premixing gases. A sapphire seated needle valve is used to very precisely control the introduction of each impurity gas into the system. To automate impurity additions, solenoid operated valves are used to control the gas that is introduced to the needle valve.

Two loops have been completed at ORNL to provide additional testing capability under low $\mathrm{He}$ flow conditions with controlled impurity levels. They are similar in design to the INL loop shown schematically above and control the impurity chemistry as noted by operating in the "bleed and feed" mode. A photograph of the ORNL loop is shown in Figure 7.

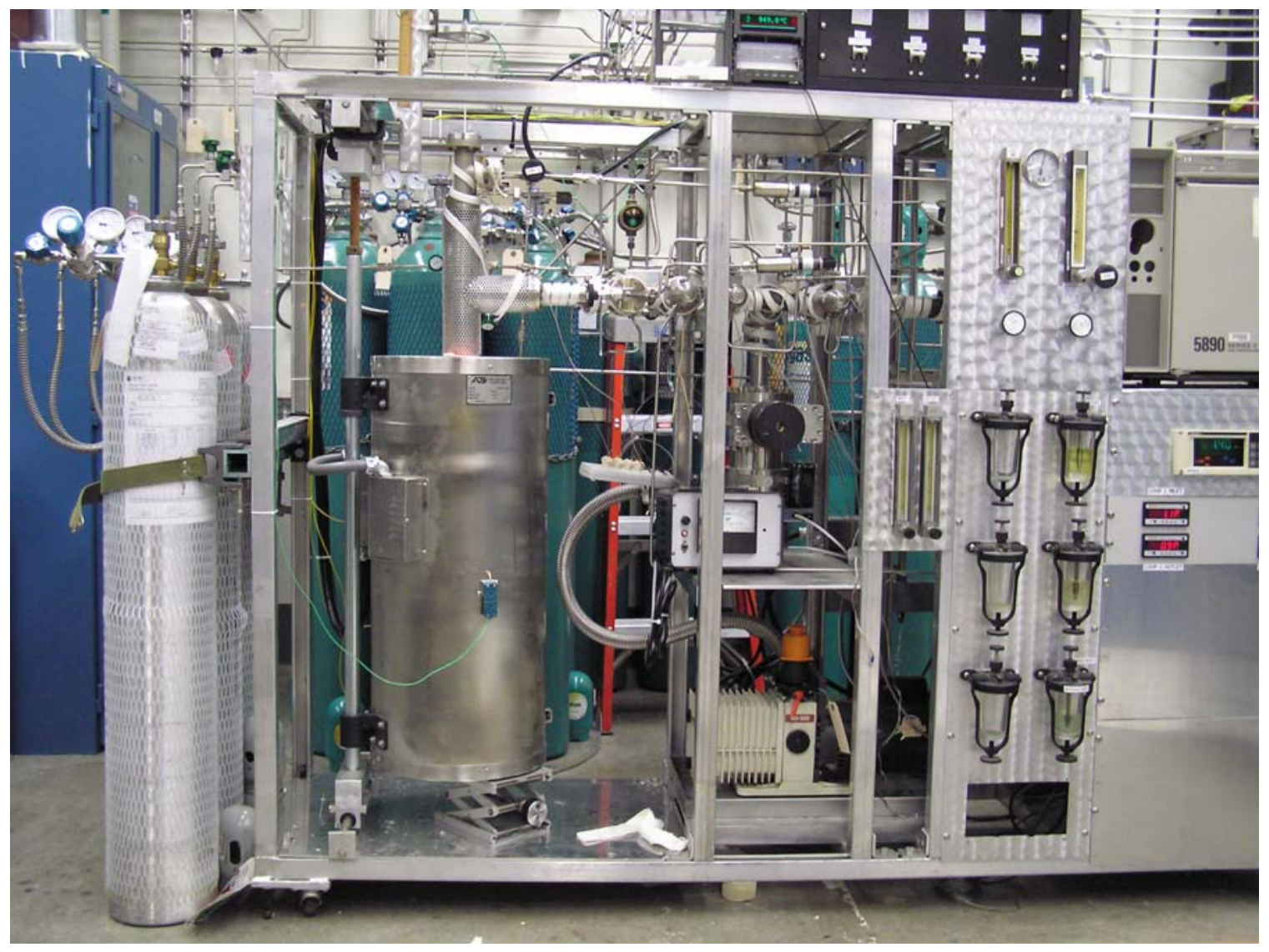

Figure 7. Photograph of the low velocity controlled impurity chemistry test loop at ORNL.

The high temperature corrosion loops currently in use for both the U.S. and French programs use gas chromatography with pulsed ionization sources to determine the impurity levels in the helium. This method has the advantage of using commercially available systems that are relatively inexpensive, require minimal calibration, and clearly distinguish between each of the impurity species. The disadvantage of this method is that the measurement time for each gas sample is typically between 10 and 20 minutes, and the lower level of detection for most of the impurities of interest is about $1 \mathrm{ppm}$. Christ et al., developed a corrosion test system using quadrupole mass spectroscopy capable of determining impurity concentrations to levels of less than $0.1 \mathrm{ppm}$ in real time. ${ }^{37}$ The system was used extensively to determine the dynamics of gas interactions with surfaces. While the system had fast response time, it had to operate at very low pressure (less than $10^{-8} \mathrm{~Pa}$ ), and, due to fragmentation of gas molecules during ionization, there were many overlapping mass peaks e.g., $\mathrm{CO}_{2}, \mathrm{~N}_{2}$ and $\mathrm{CO}$. This resulted in the need for complex methods of calibration and deconvolution of the peaks. 
Much of the current effort using the INL corrosion loop has focused on control of the gas chemistry and characterization of the ability to maintain precise control of impurity levels for sustained periods up to 1000 hours (the anticipated length of corrosion tests). Control of water is particularly difficult. As noted above, the French test loops only measure water levels, they do not attempt active control. The graph below (Figure 8) shows control of the water content at the $4 \mathrm{ppm}$ level for a sustained period followed by controlled change in the level to $2 \mathrm{ppm}$. The duty cycle of the solenoid valve is shown on the plot; this is the fraction of the time that the valve is active in controlling flow of moist helium into the loop. For a set point of $2 \mathrm{ppm}$ of water, the valve is cycling at a very low fraction of its potential; thus, this is near the lower limit of active control for this system.

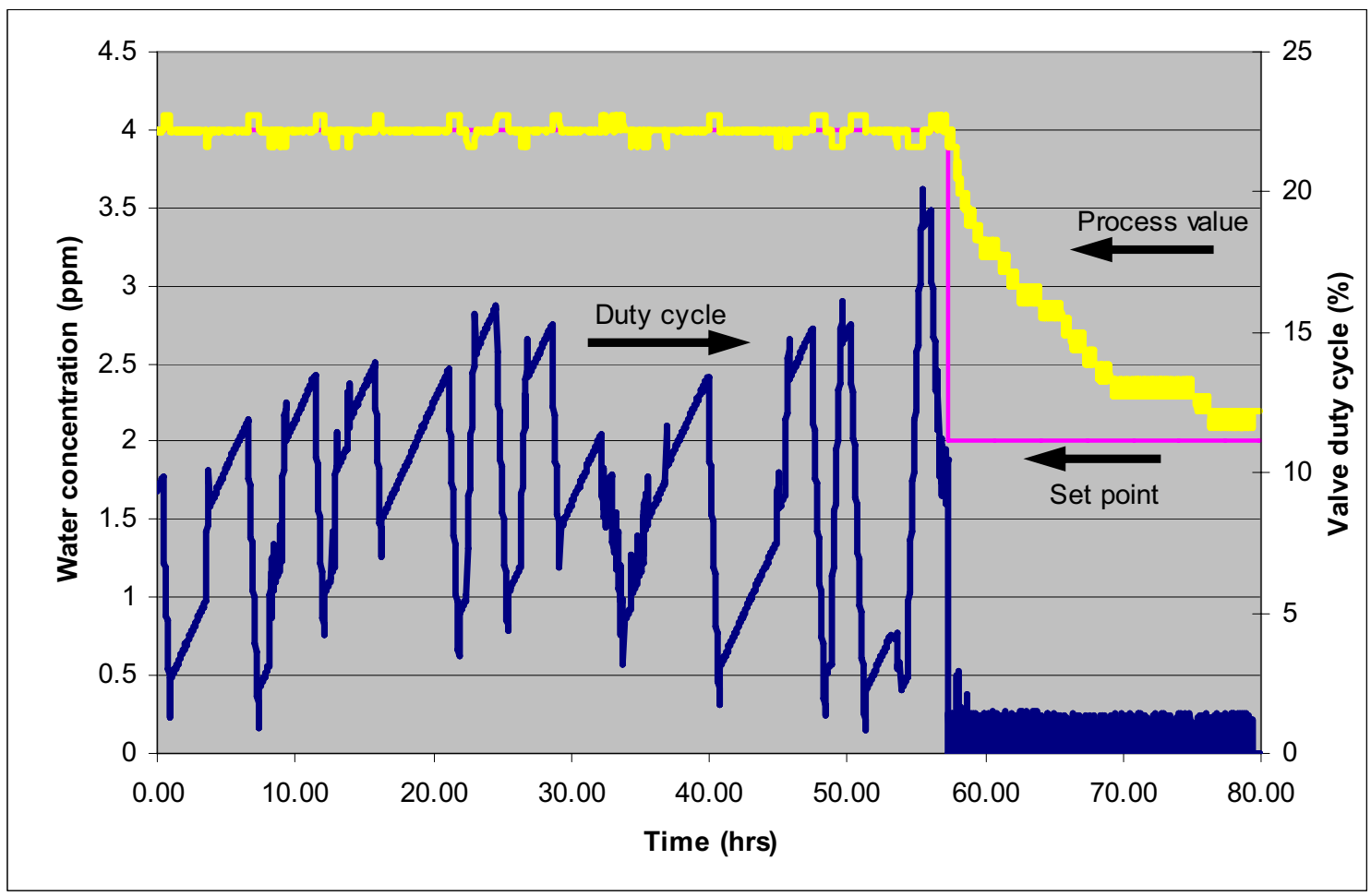

Figure 8 . This plot shows the loop water vapor content being controlled to a set point of $4 \mathrm{ppm}$ for over 50 hours. At approximately 57 hours, the set point was reduced to a value of $2 \mathrm{ppm}$. The duty cycle for the solenoid control valve immediately dropped to less than $0.5 \%$ to bring the water vapor content to 2 ppm.

As noted previously, because of the low flow rates in coupon test loops, the current U.S. and French programs intend to determine mechanisms of corrosion. Since there is no coolant chemistry that is inert with respect to Inconel 617 or Haynes 230, the overall approach of the two programs is to determine a range of impurity levels, focused primarily on $\mathrm{H}_{2} \mathrm{O}$ and $\mathrm{CO}$, where the environmental interaction is slightly oxidizing at the temperatures of interest. To date, the INL and ORNL have completed design, construction, and performance confirmation of low velocity loops. During DOE Fiscal Year 2007 coupon testing will be initiated. The U.S. program intends to focus primarily on experimental confirmation of the modified Ellingham diagrams that describe corrosion mechanisms at higher temperatures than previous studies and on coupons containing fusion welds. The French program will carry out similar characterizations; however, that program has a particular focus on establishing the upper limit on service temperature determined by the microclimate reaction. ${ }^{36}$ 
Both the U.S. and French programs are investigating Inconel 617 alloys with restrictions on particular alloy elements to optimize some property, but which remain within the ASTM specification. The French program has obtained a heat of Inconel 617 with minimum levels of Al and Ti with the anticipation that this modification will reduce the amount of internal oxidation along grain boundaries as shown in Figure 3. The U.S. program has determined that optimum creep properties at the highest temperatures require the maximum allowable levels of $\mathrm{Al}$ and $\mathrm{Ti}$ and a heat of Inconel 617 with this type of chemistry has been obtained. It should be noted that Haynes 230 has been selected for parallel studies because it appears to have comparable creep properties compared to Inconel 617 and perhaps displays less internal oxidation.

\section{Aging Effects in Inconel 617}

Concern about potential changes in microstructure and properties associated with long term exposure at high temperature resulted in a long term aging study for Inconel 617 that has been in progress for a year. Material from two commercial heats, one $12.5 \mathrm{~mm}$ in thickness and another $18 \mathrm{~mm}$ in thickness, has been aged in laboratory air at temperatures of 800 and $1000^{\circ} \mathrm{C}$. The microstructure and mechanical properties have been characterized in the as-received condition and after various aging times.

The microstructure of the as-received $12.5 \mathrm{~mm}$ thick plate in the mill annealed condition is shown in a montage of optical micrographs in Figure 9. The rolling direction, short and long transverse directions are indicated in the figure. It is evident that the microstructure is not homogeneous. There are bands of fine and coarse grains and inhomogeneous distribution of carbides. This inhomogeniety is related to the ingot solidification and subsequent rolling operations used to form plate and is representative of commercial products.

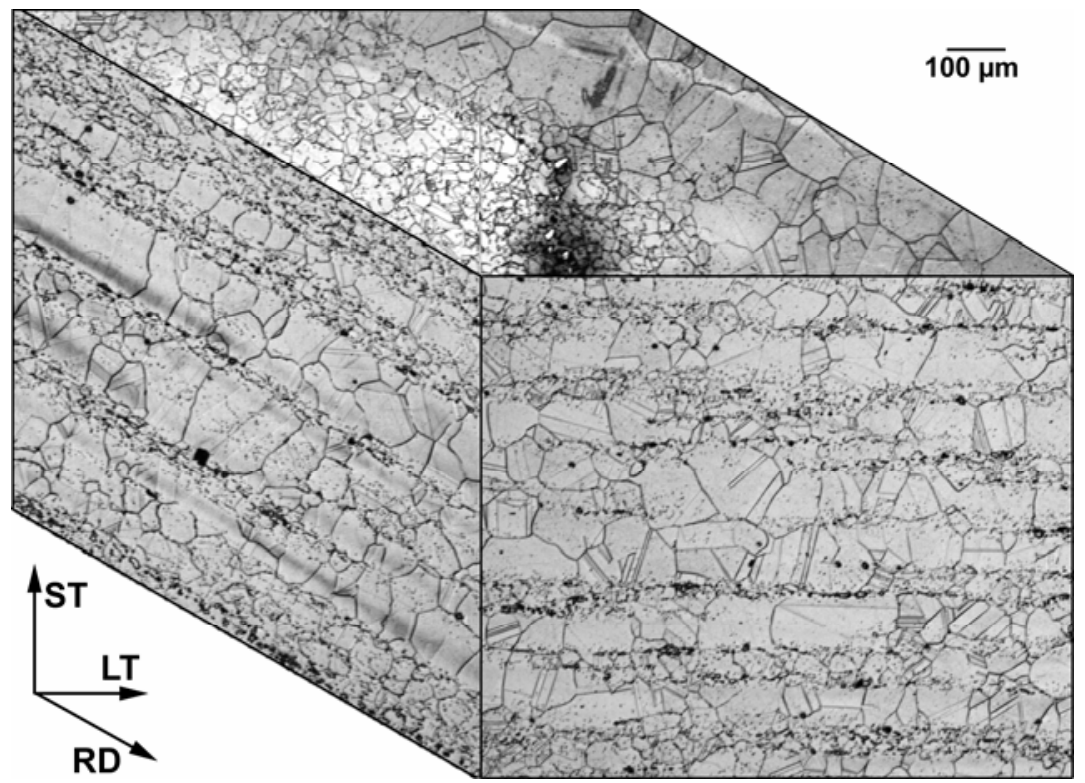

Figure 9. Montage of optical micrographs showing the grain size and carbide distribution in as-received Inconel 617 plate. The dolling direction (RD), short transverse (ST) and long transverse (LT) directions are noted.

Optical micrographs of cross-sections through coupons of Inconel 617 aged for 30 and 3,000 hours at $1000^{\circ} \mathrm{C}$ are shown in Figure 10. Methods were developed to produce nickel plating on the surface of the coupons to aid in retention of the oxide layer during sample preparation. The nickel is apparent as the mottled layer in the micrographs of aged material shown below. Using this plating layer necessitated an 
alternative to the normal etching method since conventional etches preferentially attack and remove the pure nickel. An alternative was developed based on a bromide solution that does not appreciably affect the plating while etching the Alloy 617 to reveal the carbides.

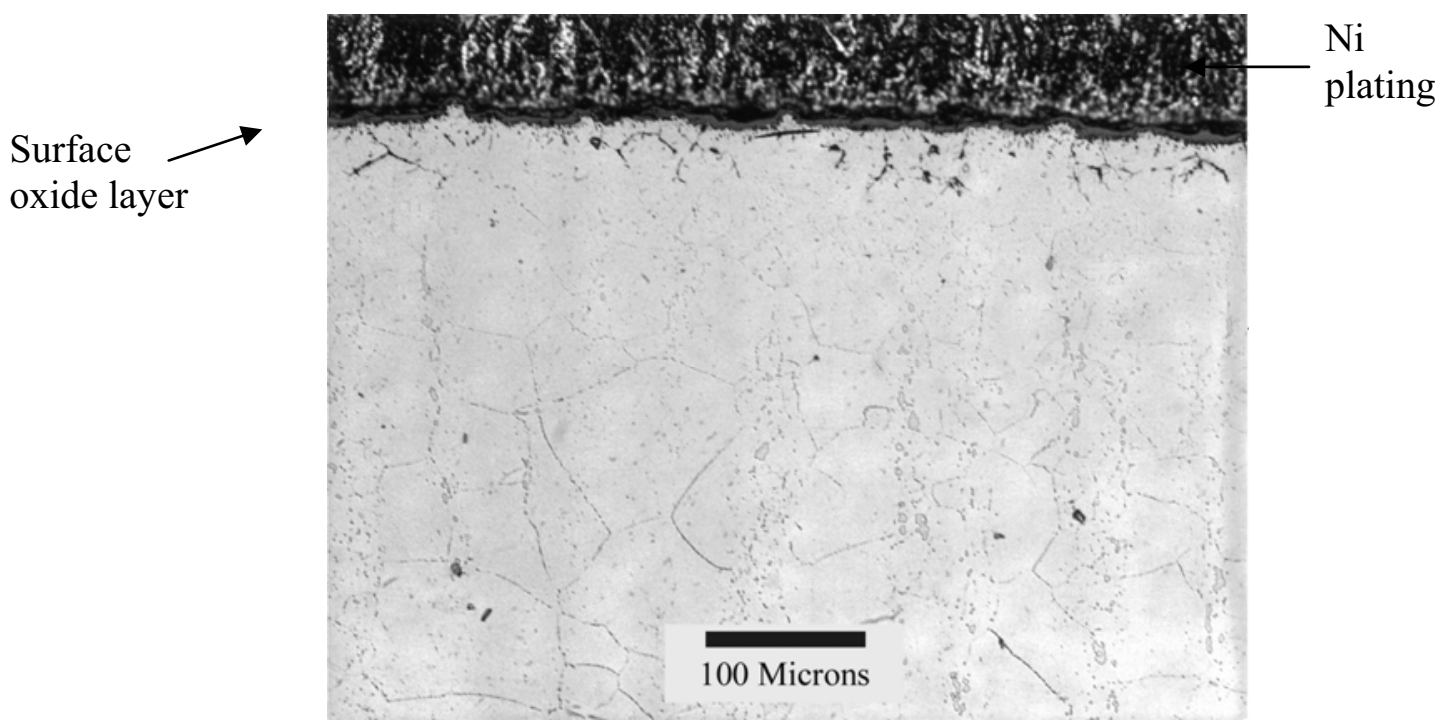

(a)

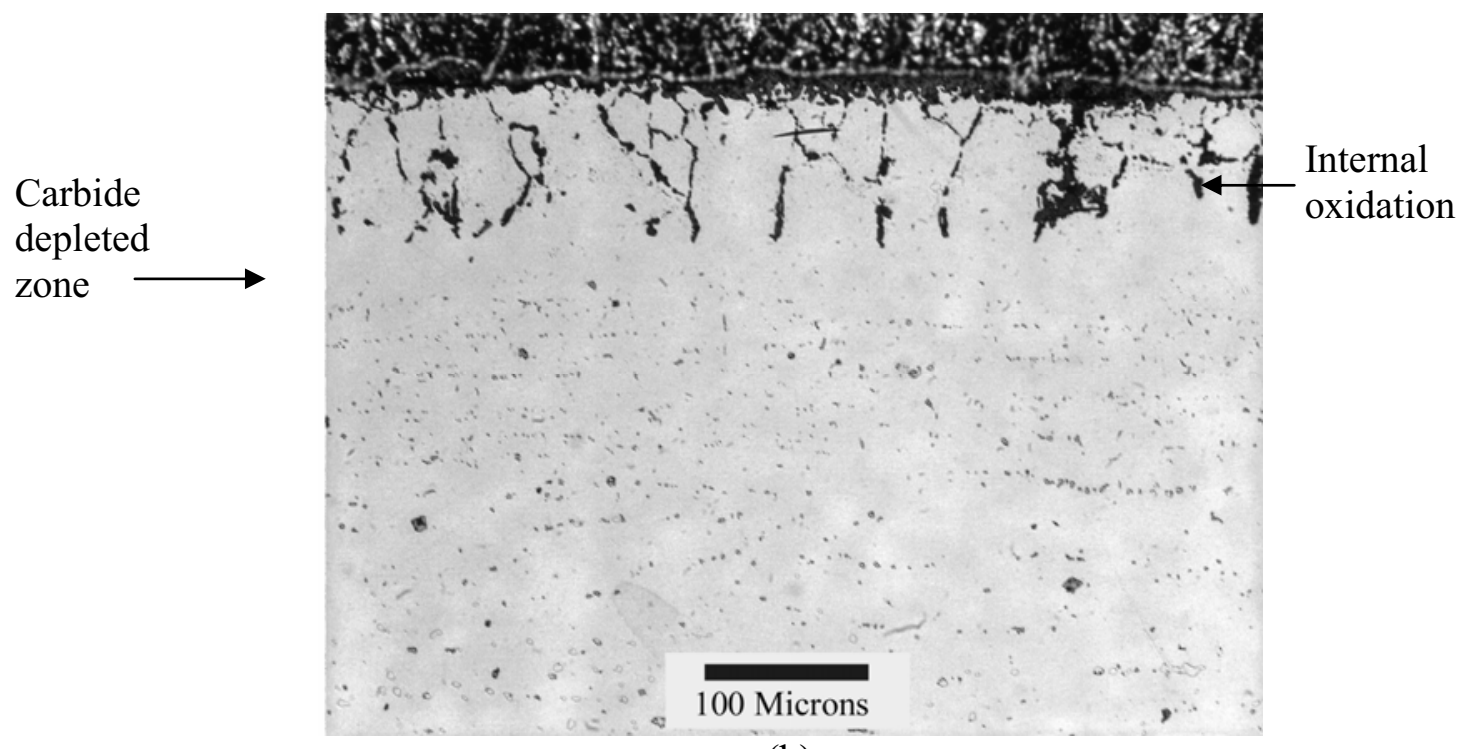

(b)

Figure 10. Optical micrographs of Alloy 617 aged in air for (a) 30 and (b) 3000 hours at $1000^{\circ}$.

Three microstructure features are of interest in these studies. They are the oxide thickness, depth of internal oxidation and the depth of the carbide depleted zone. These three regions are shown in the micrograph in Figure 11 and labeled A, B, and C respectively. By quantifying the time dependence of changes in microstructure features, the mechanism of degradation can be ascertained. Data for the depth of carbide depleted zone in the $20 \mathrm{~mm}$ thick plate are shown in Figure 12. It has been reported in similar studies that this behavior is indicative of carbide dissolution due to chromium migration to support oxide formation on the surface. In contrast, dissolution of carbides due to a decarburization reaction at the surface results in linear change in depth of depleted zone with increasing time. 


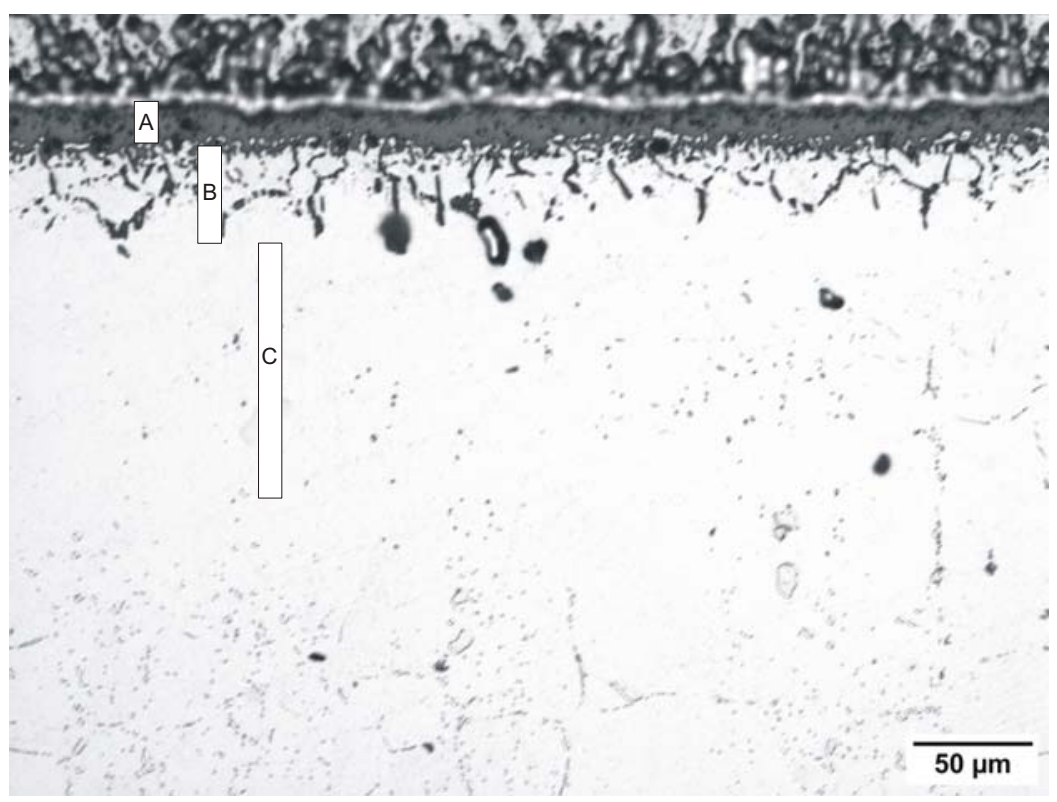

Figure 11. Alloy 617 exposed in air for 1000 hours at $1000^{\circ} \mathrm{C}$. The thickness of oxide, extent of internal oxidation and depth of carbide depletion are shown as regions $\mathrm{A}, \mathrm{B}$, and $\mathrm{C}$, respectively.

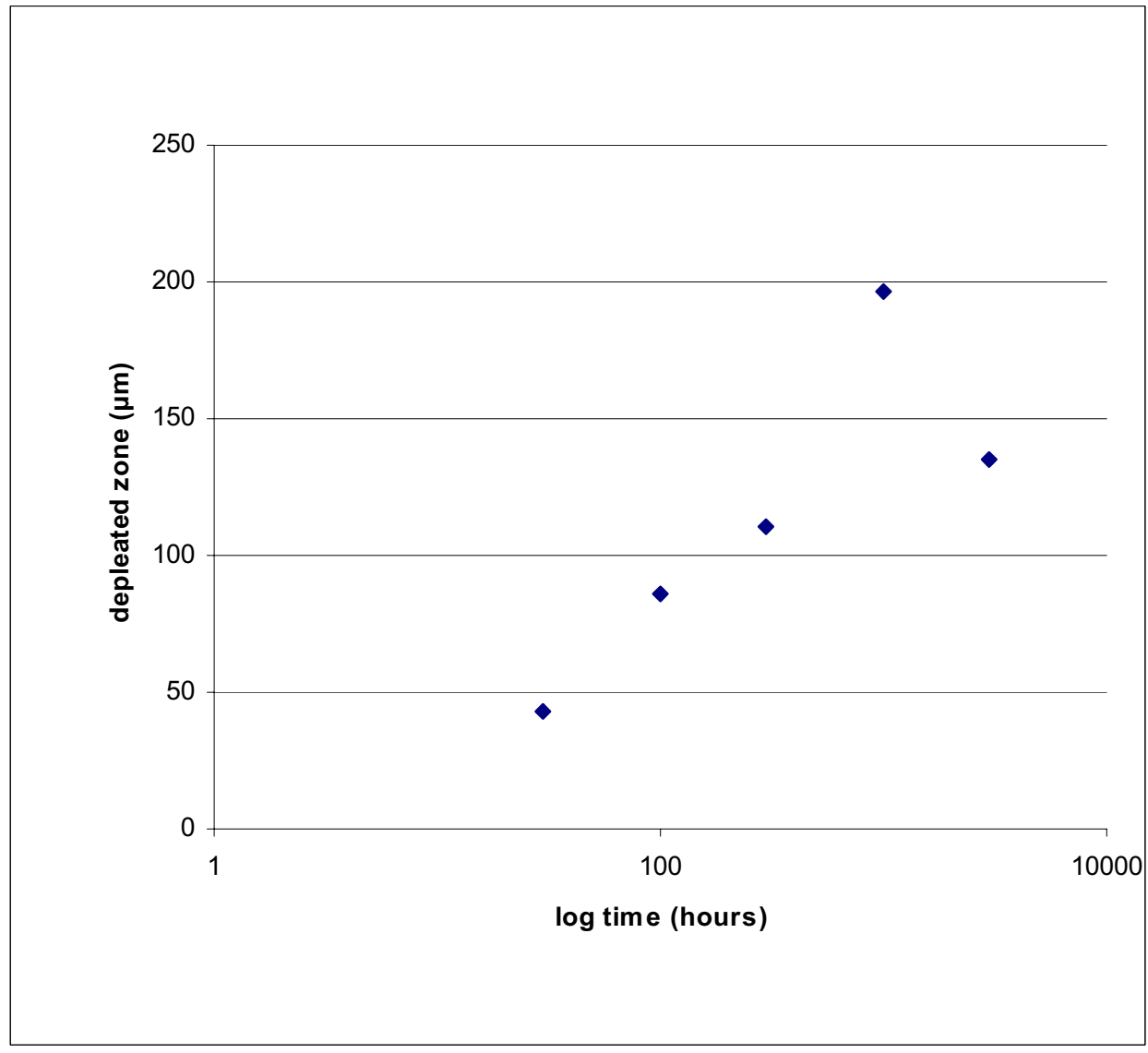

Figure 12. Depth of carbide depleted zone as a function of time in a $20 \mathrm{~mm}$ thick Alloy 617 plate exposed in air at $1000^{\circ} \mathrm{C}$ 
Scanning electron microscopy characterization was carried out on the 12.5 and $18 \mathrm{~mm}$ thick plates. Backscattered electron images at two different magnifications are shown in Figure 13 and the corresponding secondary images are shown in Figure 14 for $12.5 \mathrm{~mm}$ thick plate aged for 1000 hours. The backscattered electron images provide information principally based on the atomic number of the feature. Oxides appear dark in these images. The secondary electron images contain information on both topography and composition. The images are complementary, allowing differentiation between oxides and voids for example.
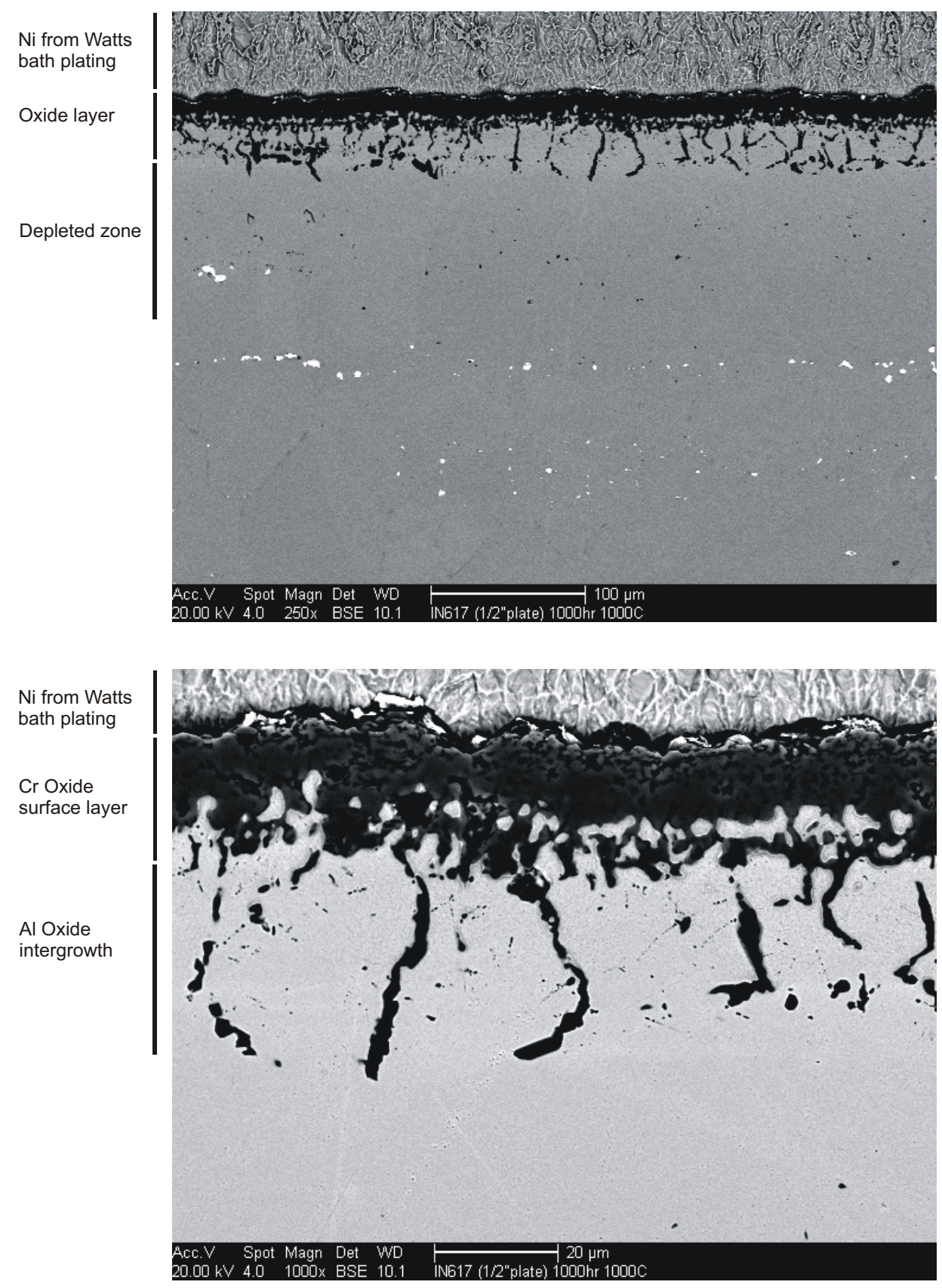

Figure 13. Backscattered electron images of $12.5 \mathrm{~mm}$ thick Inconel 617 plate aged in air for 1000 hours. 

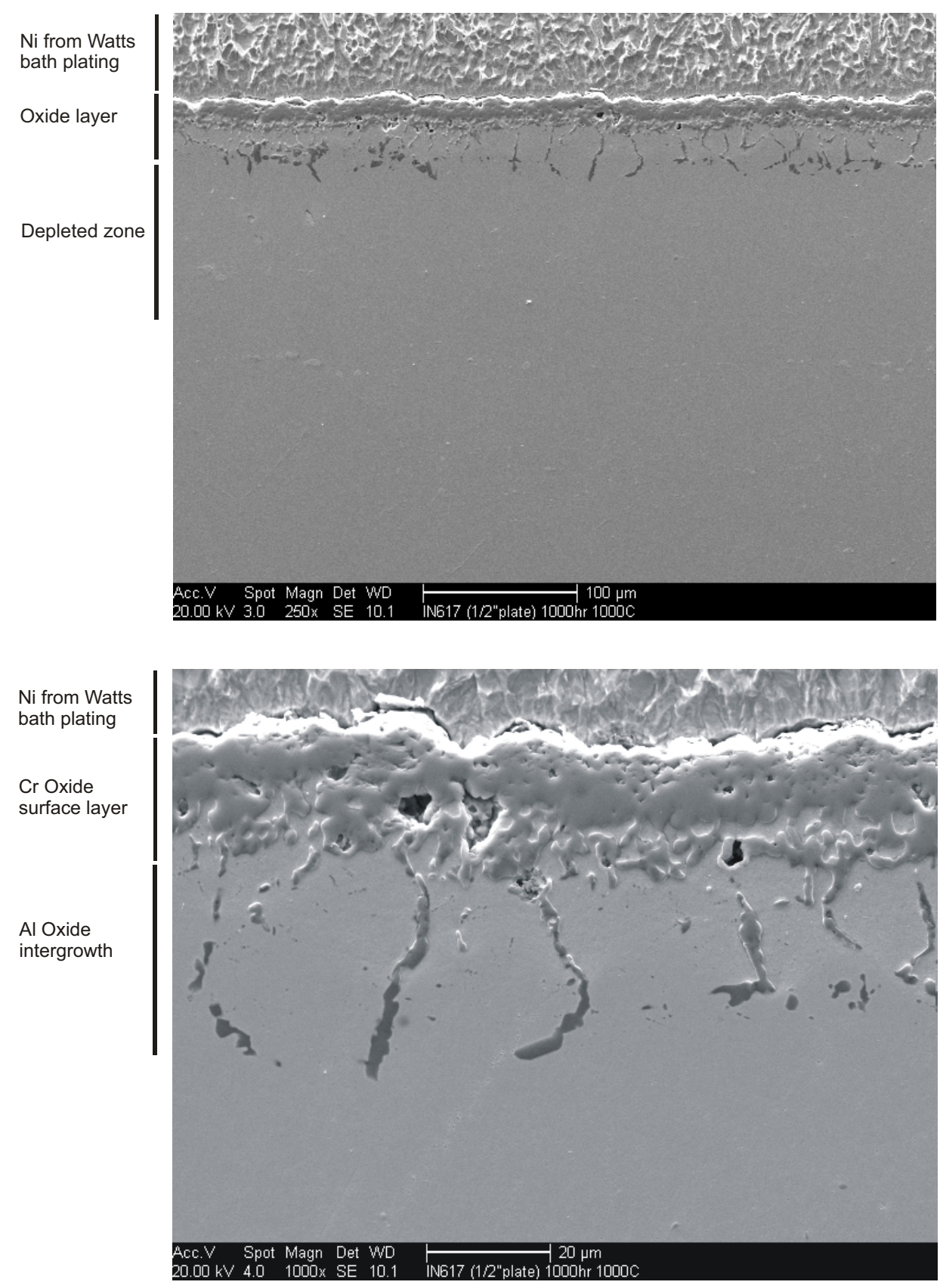

Figure 14. Secondary electron images of $12.5 \mathrm{~mm}$ Inconel 617 plate aged for 1000 hours in air.

Scanning electron micrographs were used to quantify the grain size distribution as a function of aging time for the two different temperatures in both plates. Representative plots of the grain size distribution are shown in Figures 15 a-e below for the $12.5 \mathrm{~mm}$ thick plate aged at $800^{\circ} \mathrm{C}$. Grain size data for both aging temperatures are summarized in Figure 16. In this plot, the average grain size is determined from the $50 \%$ cumulative percent value. It can be seen from this figure that in general there is only modest increase in grain size with increasing aging time and the distribution of grain sizes broadens with increasing exposure time. Note that the apparent average grain size does not increase monotonically with increasing time at temperature. This inconsistency is most likely related to the extensive banding observed in the as-received plate. 


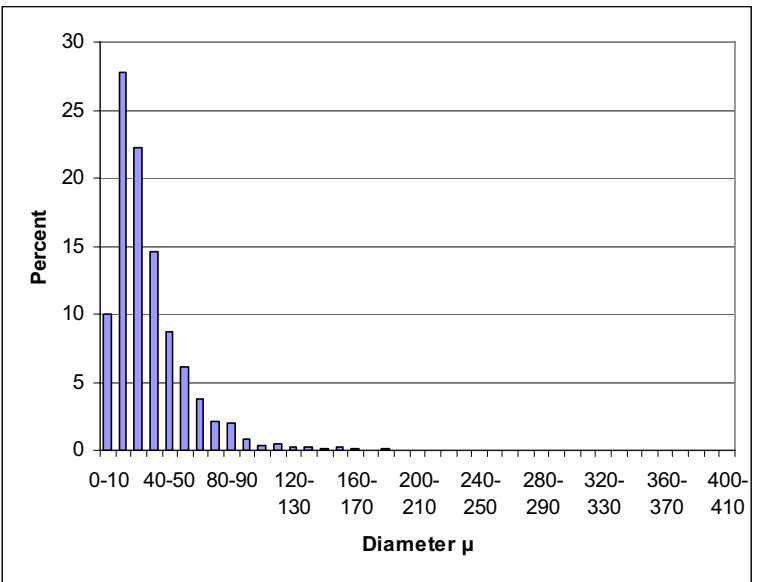

(a)

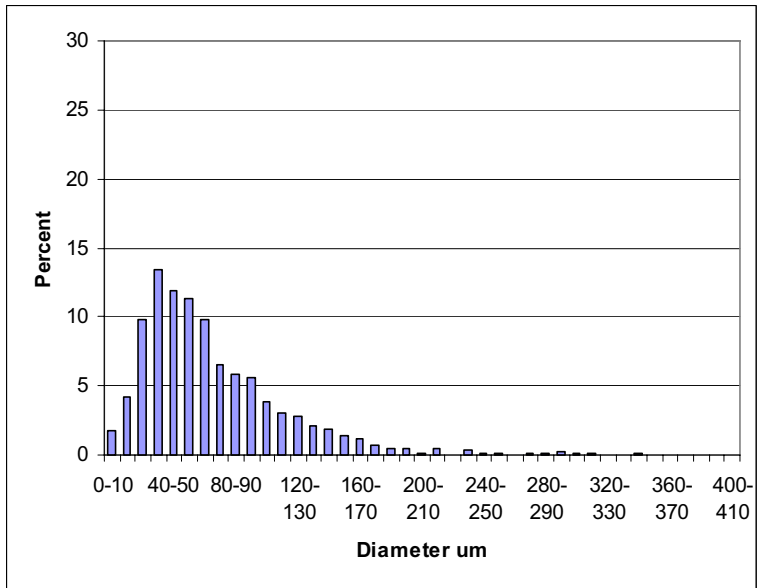

(c)

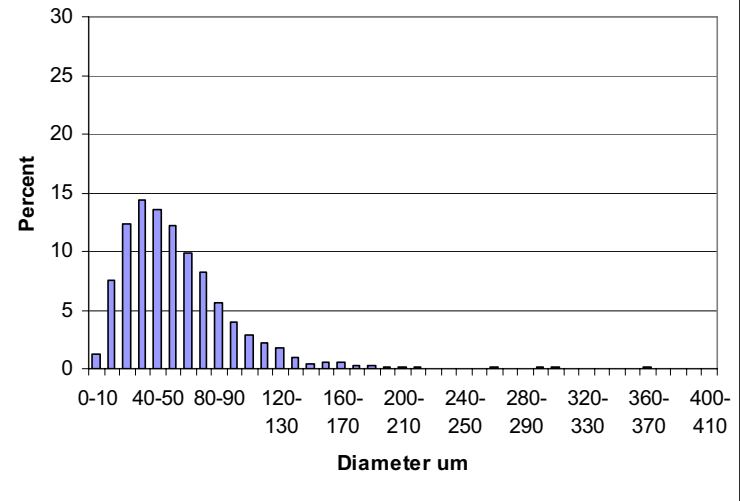

(b)

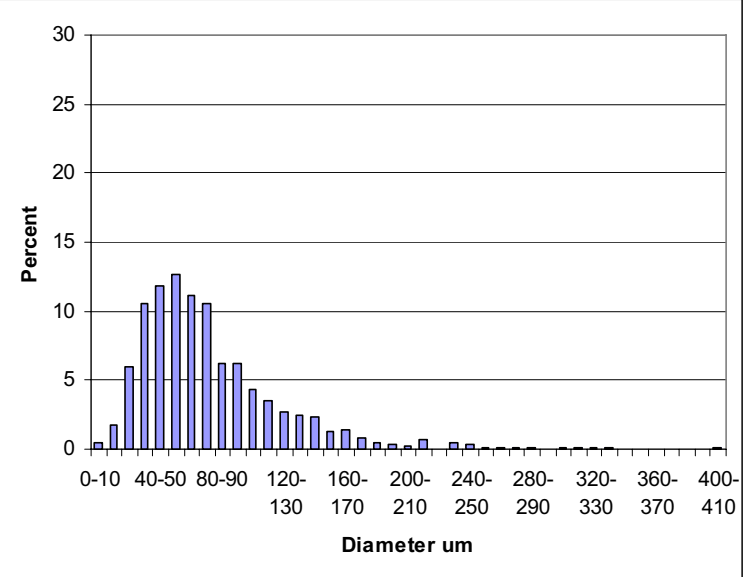

(d)

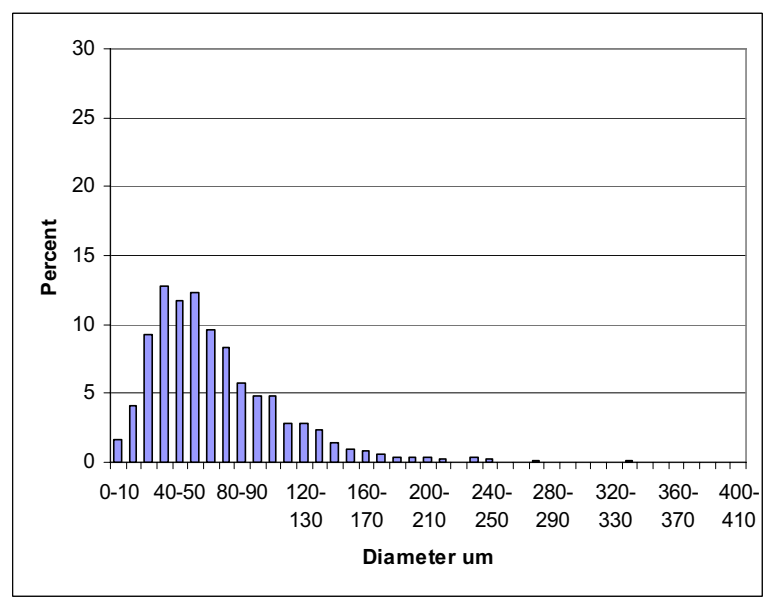

(e)

Figure 15 a-e. Grain size distributions for Inconel 617 (a) in the as-received condition and (b) and (c) aged at $800^{\circ} \mathrm{C}$ for 1000 and 3000 hours and (d) and (e) aged at $1000^{\circ} \mathrm{C}$ for 1000 and 3000 hours. 


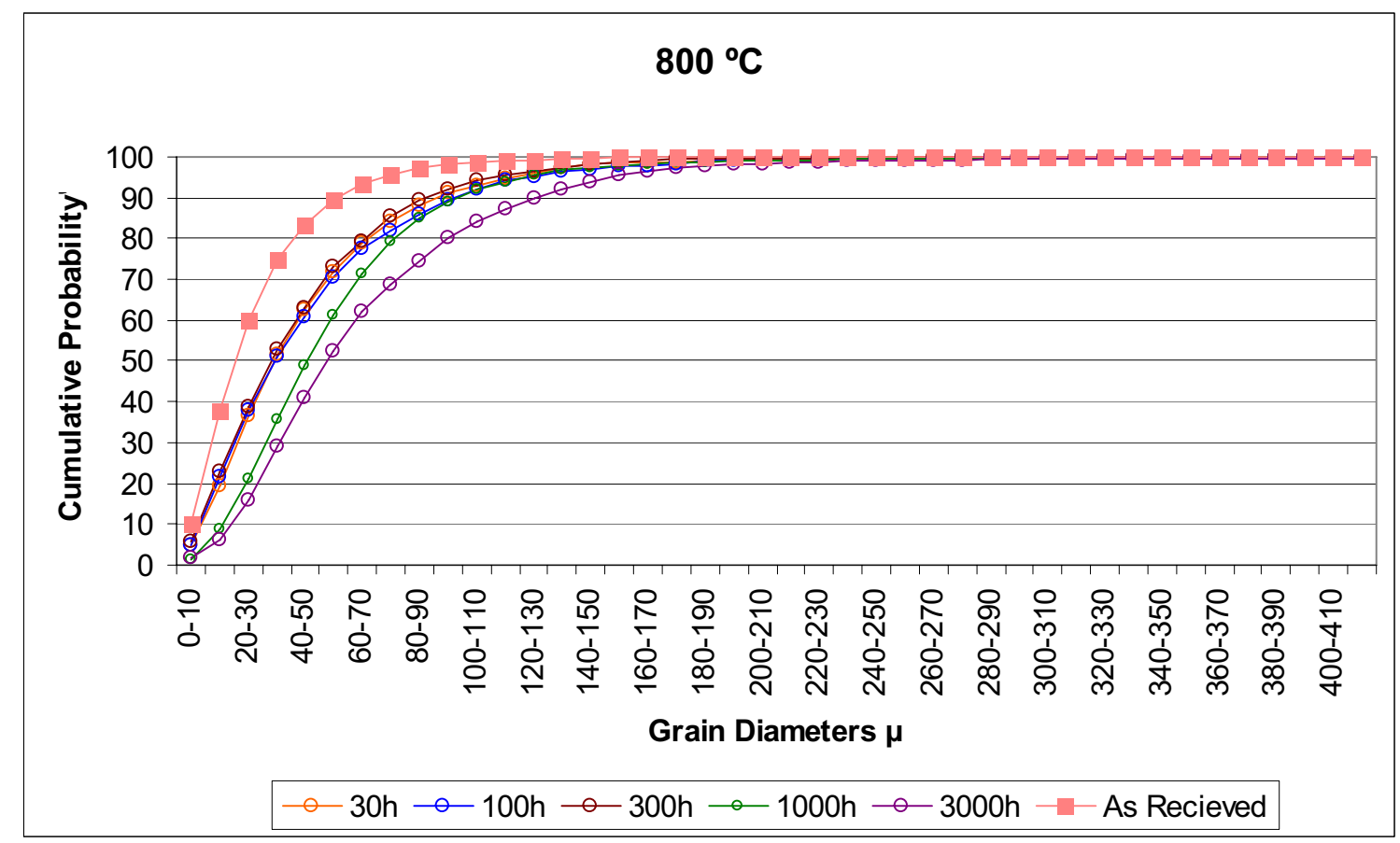

(a)

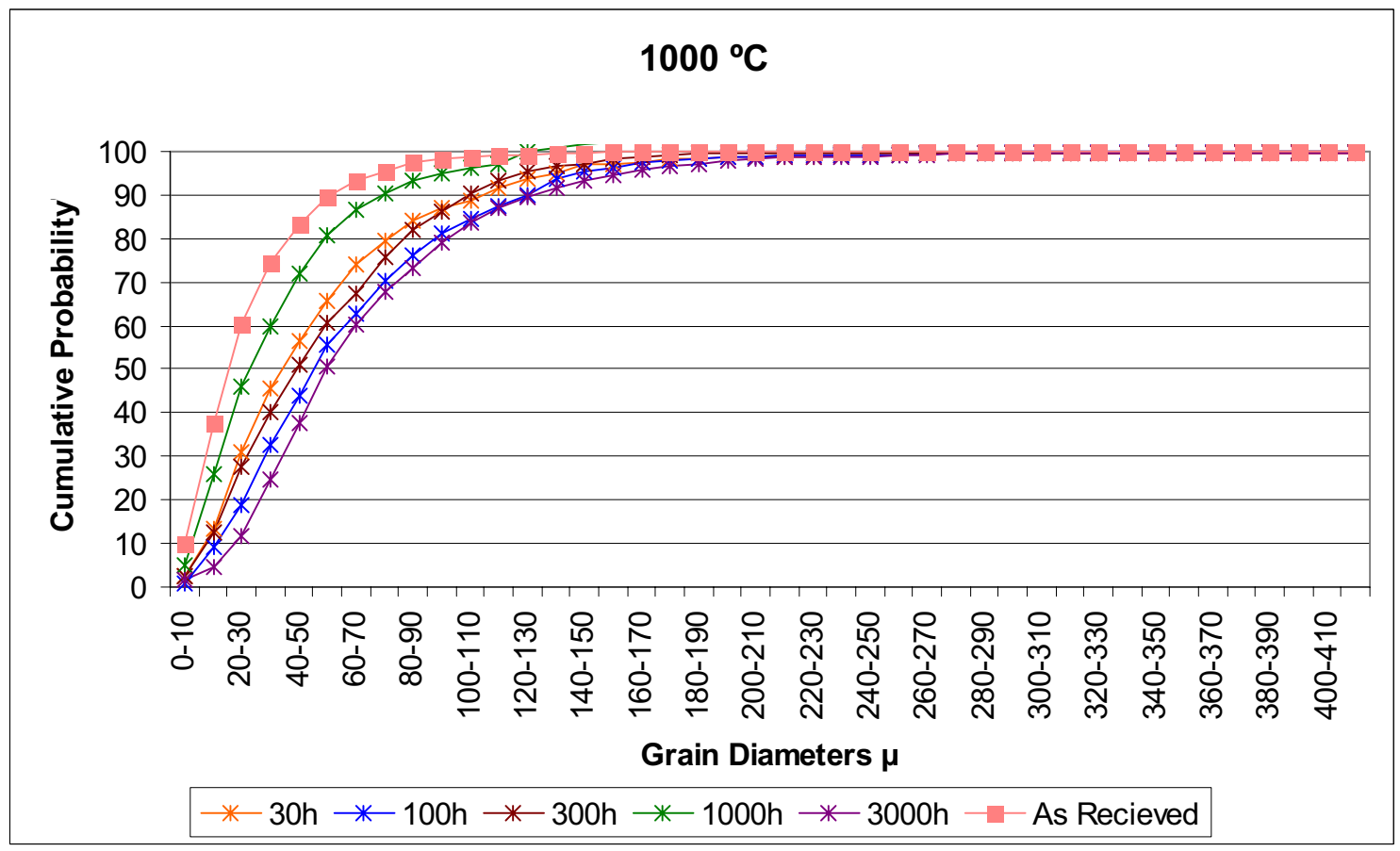

(b)

Figure 16. Cumulative grain size for $12.5 \mathrm{~mm}$ thick Inconel 617 plate aged at (a) $800^{\circ} \mathrm{C}$ and (b) $1000^{\circ} \mathrm{C}$.

Mechanical property results for the Inconel 617 aged at $1000^{\circ} \mathrm{C}$ for 100 and 1000 hours are shown in Tables 5 and 6 below. The numerical values for tensile properties are the average for two tests and the Charpy impact energies represent the mean of three tests. The orientation of the Charpy test bars with respect to the alloy plate orientation is shown schematically in Figure 17. Tensile properties of the plate 
in the mill annealed condition are comparable to the aged values. The yield strength, UTS and ductility in the mill annealed condition are $404 \mathrm{MPa}, 809 \mathrm{MPa}$ and 50\%, respectively. The results of studies for the relatively short times examined to date indicate that there are minimal changes associated with aging time. There is perhaps a small increase in tensile properties upon increasing the aging time from 100 to 1000 hours.

Table 5. Tensile properties of Inconel 617 aged at $1000^{\circ} \mathrm{C}$ in air. Mechanical property characterization was done in air at room temperature, 800 and $1000^{\circ} \mathrm{C}$.

\begin{tabular}{ccccc}
\hline Aging Condition & Test Temp & Yield Strength, MPa & UTS, MPa & Elongation \\
\hline Mill Anneal & RT & 404 & 809 & 0.50 \\
\hline $100 \mathrm{hr} @ 800^{\circ} \mathrm{C}$ in & & & & \\
air & $\mathrm{RT}$ & 479 & 921 & 0.41 \\
& $800^{\circ} \mathrm{C}$ & 338 & 451 & 0.42 \\
\hline $1000 \mathrm{hr} @ 800^{\circ} \mathrm{C}$ in air & $\mathrm{RT}$ & 449 & 923 & 0.39 \\
& $800^{\circ} \mathrm{C}$ & 296 & 465 & 0.43 \\
\hline $100 \mathrm{hr} @ 1000^{\circ} \mathrm{C}$ in air & $\mathrm{RT}$ & 377 & 887 & 0.48 \\
& $800^{\circ} \mathrm{C}$ & 257 & 423 & 0.49 \\
& $1000^{\circ} \mathrm{C}$ & 141 & 142 & 0.58 \\
\hline $1000 \mathrm{hr} @ 1000^{\circ} \mathrm{C}$ in air & $\mathrm{RT}$ & 403 & 900 & 0.48 \\
& $800^{\circ} \mathrm{C}$ & 269 & 423 & 0.48 \\
& $1000^{\circ} \mathrm{C}$ & 135 & 144.5 & 0.592 \\
\hline
\end{tabular}

Table 6. Room temperature Charpy impact values for Inconel 617 aged at $1000^{\circ} \mathrm{C}$.

\begin{tabular}{cc}
\hline ID of specimen/orientation & Impact energy (Joules) \\
\hline Mill Anneal L-S & 265 \\
Mill anneal L-T & 166 \\
$100 \mathrm{hr} \mathrm{L-S}$ & 118 \\
$100 \mathrm{hr} \mathrm{L-T}$ & 104 \\
$1000 \mathrm{hr} \mathrm{L-S}$ & 115 \\
$1000 \mathrm{hr} \mathrm{L-T}$ & 104 \\
\hline
\end{tabular}

The impact properties are quite significantly affected by 100 hour aging compared to the mill annealed condition. The impact energy in the L-S orientation in the as-received material is $265 \mathrm{~J}$ and in the L-T orientation the value is $166 \mathrm{~J}$. Presumably the reduction in impact energy is related to the precipitation of large carbides on the grain boundaries after initial aging, but confirmation awaits completion of the microstructural characterization. There is an effect of specimen orientation with respect to the rolling direction noted in the Charpy impact tests, however, there is no effect observed from aging beyond 100 hours. The effect of orientation is caused by the banded structure previously reported for this plate resulting from solidification and hot working. 


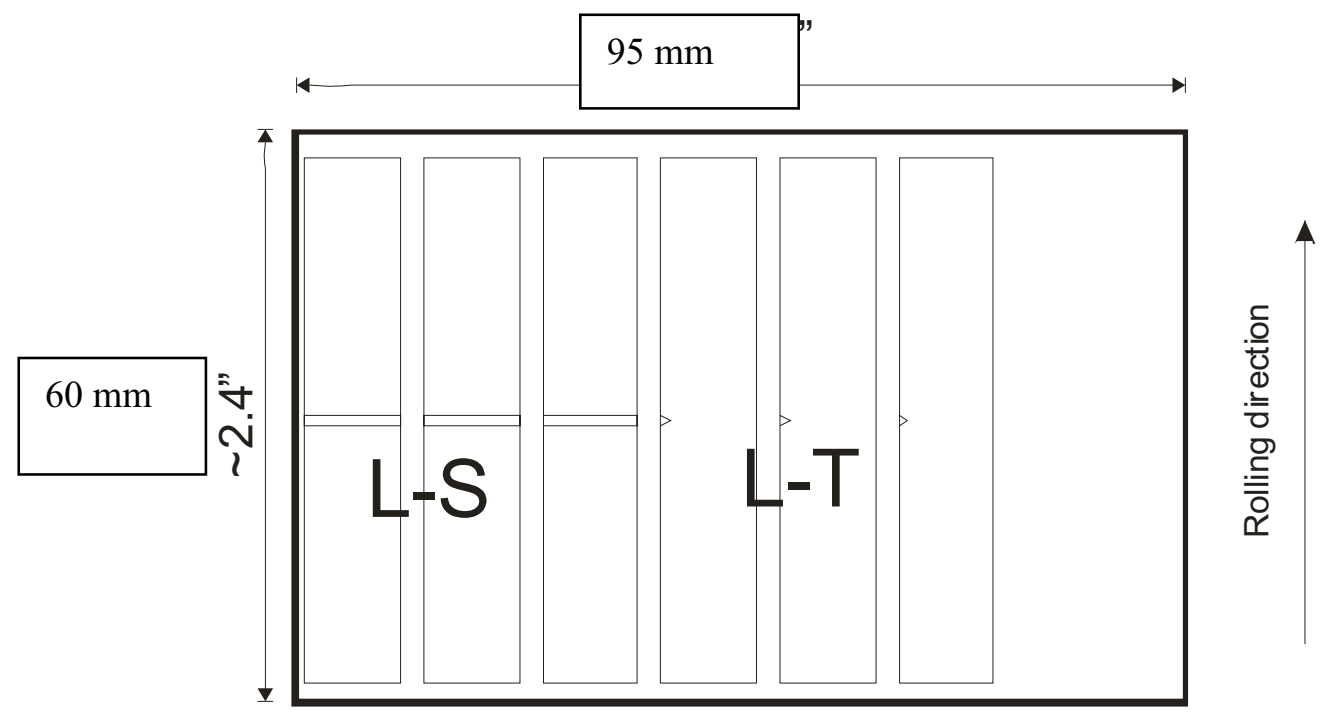

Figure 17. Orientation of the Charpy impact bars with respect to the Inconel 617 plate.

\section{Aging Haynes 230}

Baseline testing of Haynes alloy 230 has been initiated. Characterization of the microstructure and tensile properties of the as-received plate has been completed. ${ }^{38}$ A montage of photographs from optical microscopy illustrating the general features of the Hynes 230 plate microstructure is shown in Figure 18. Note that this plate is somewhat more homogeneous that the Inconel 617 plate shown in Figure 9 above. Aging of this material in air has only recently begun and results of these studies are not yet available. Revision of the aging test plan based on reduction in the expected outlet temperature of the NGNP has resulted in planned aging schedule of up to 10,000 hours at temperatures of 750,850 and $9500^{\circ} \mathrm{C}^{39}$

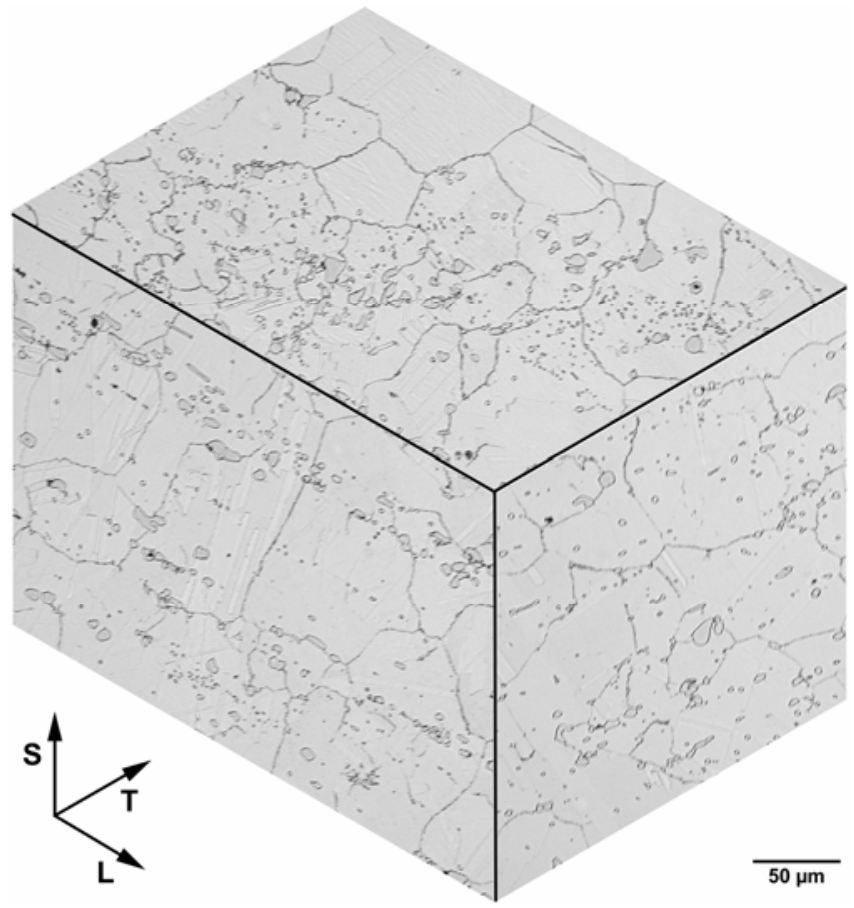

Figure 18. Aging will continue with similar characterization as the Inconel 617. 


\section{7. $\quad$ Aging Under Load}

Aging studies have generally shown that long term exposure of Inconel 617 to high temperature in the absence of a load results in general coarsening of the carbides, however the distribution of carbides remains little changed. ${ }^{40}$ In contrast, aging Inconel 617 under tensile load at $1000^{\circ} \mathrm{C}$ results in substantial redistribution of the carbides from grain boundaries parallel to the stress axis to those normal to the tensile axis (and under tensile stress). ${ }^{41}$ This behavior is thought be deleterious to the creep properties due to the resulting instability in the microstructure. The boundaries that are denuded of carbides are free to rapidly migrate at these high temperatures. A small collaborative project has been initiated with Boise State University to examine this phenomenon in detail. The range of temperatures for which significant redistribution of carbides occurs and the crystallography of the boundaries that seem to be particularly affected by this process are being examined for Inconel 617. A similar study of the behavior of Haynes has recently been initiated in collaboration with the University of Missouri.

A summary of creep experiments for Inconel 617 is shown in Table 7. Two samples showed evidence of preferential precipitation on the grain boundaries that were in tension and two did not based on characterization using optical metallography. The sample labeled, TML-IN617-05 (Grip End), was included as a stress free control sample and was taken from the grip end where the creep stress should have been very small compared the other samples which were taken from the gage section of each creep specimen.

Table 7: Summary of Creep Conditions

\begin{tabular}{ccccc}
\hline Sample ID & $\begin{array}{c}\text { Creep } \\
\text { Temperature, } \\
\mathbf{0}^{\mathbf{C}}\end{array}$ & $\begin{array}{c}\text { Creep Stress, } \\
\text { MPa }\end{array}$ & $\begin{array}{c}\text { Creep Time, } \\
\text { hrs }\end{array}$ & $\begin{array}{c}\text { Preferential } \\
\text { Precipitation } \\
\text { (Yes/No) }\end{array}$ \\
\hline TML-IN617-01 & 1000 & 24.5 & 202 & Yes \\
TML-IN617-02 & 900 & 50 & 100 & No \\
TML-IN617-03 & 900 & 50 & 217 & Yes \\
TML-IN617-05 & 900 & 24.4 & 238 & No \\
TML-IN617-05 & 900 & 24.4 & 238 & No \\
(Grip End) & & & & \\
\hline
\end{tabular}

In addition to optical microscopy, 5 samples were examined by EBSD Analytical, Inc. in Utah to run some Orientation Imaging Microscopy (OIM) scans on the samples in the Table. The samples were polished, etched using a bromine-containing etch and then put back into a vibratory polisher (using 0.05 micron colloidal silica) for 2 hours to remove the etching relief. Although these samples were not electro polished at all, the Electron Back-scatter Diffraction (EBSD) patterns were very good.

EBSD Analytical scanned 150 micron by 150 micron area with a step size of 0.25 microns on a FEG-SEM for a total of around 400,000 points per scan. The samples seemed to show areas (bands) of large grains alternating with bands of much smaller grains based upon optical metallography observations. Therefore EBSD Analytical ran two scans on each sample - one in the large grain areas and one in the smaller grain sized areas for comparison purposes. In addition to the orientation data Energy Dispersive Spectroscopy (EDS) data were also collected for each point.

Figure 19 is an image generated from image quality data. Software assigns a value to the EBSD pattern based on the quality of the pattern, so instead of generating an image from the crystal orientation 
data typically used in OIM the image is created using the image quality value for each point in the scan. This process results in a very good image, including grain boundaries and precipitates.

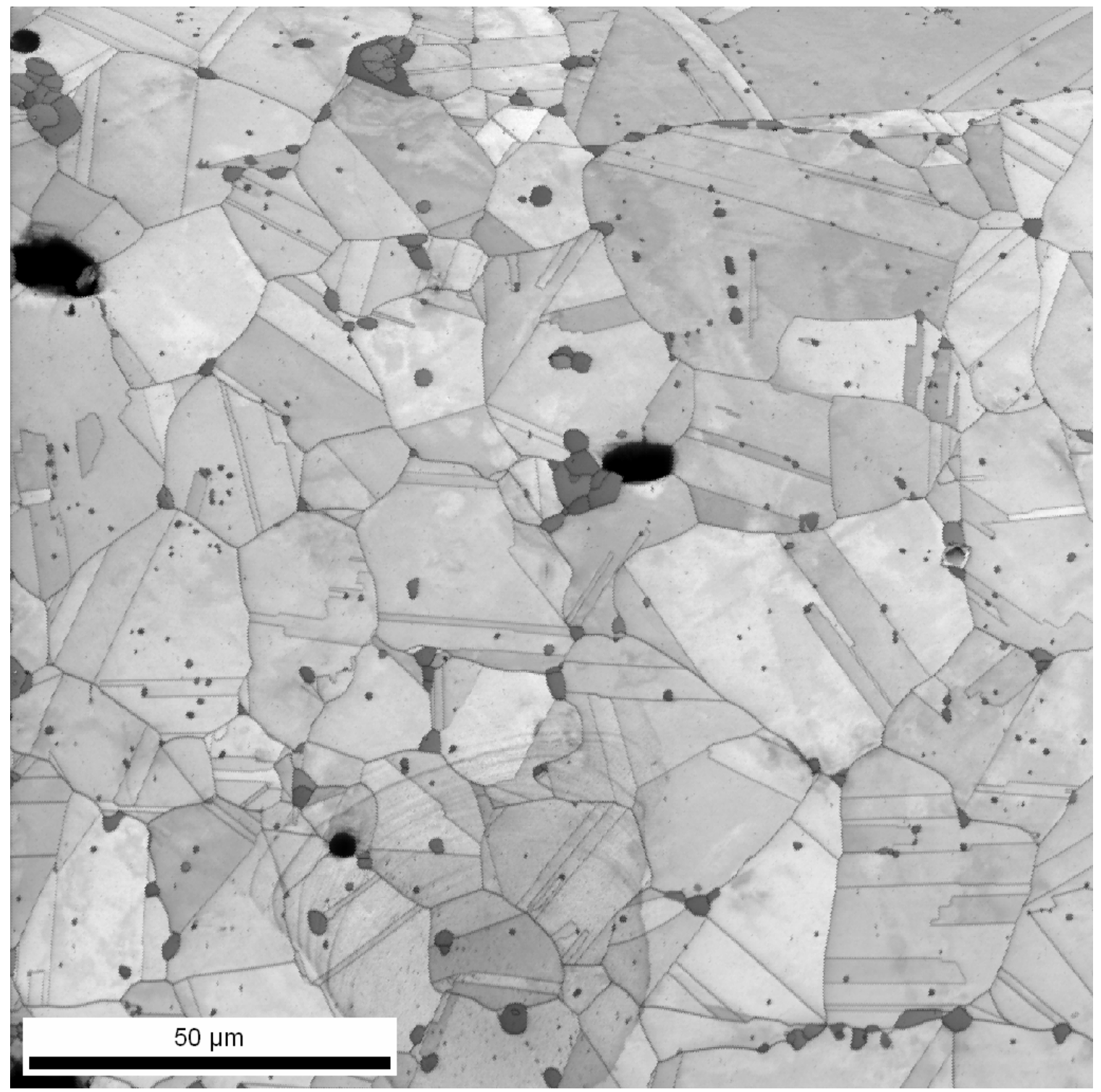

Figure 19. Image of sample TML-IN617-01, small grain area.

The precipitates show two slightly different shades of grey as well as a few very black particles, generally larger than the grey particles. Figure 20 shows images generated from the EDS data. All images in Figure 20 are taken from the same area but generated from different information - 20a) is again the image quality map, b) is the aluminum map, c) is the chromium map and so on. Aluminum shows very little segregation and is generally uniformly spread through the matrix. However, the rest of the elements segregate to the precipitates to different extents. Also, careful study of these images reveals there are three types of precipitates, presumably carbides. Immediately obvious are the chromium and molybdenum precipitates. These appear to be essentially stoichiometric, with little or no inclusion or substitution of the other elements. The third precipitate is present in low numbers (there are only four in this area) and correspond to the black precipitates in the image generated from image quality. These appear to be composed of chromium, cobalt, nickel and a small amount of iron. This finding opens up the 
possibility that specific types of precipitates might preferentially migrate to boundaries under tension while others may not.

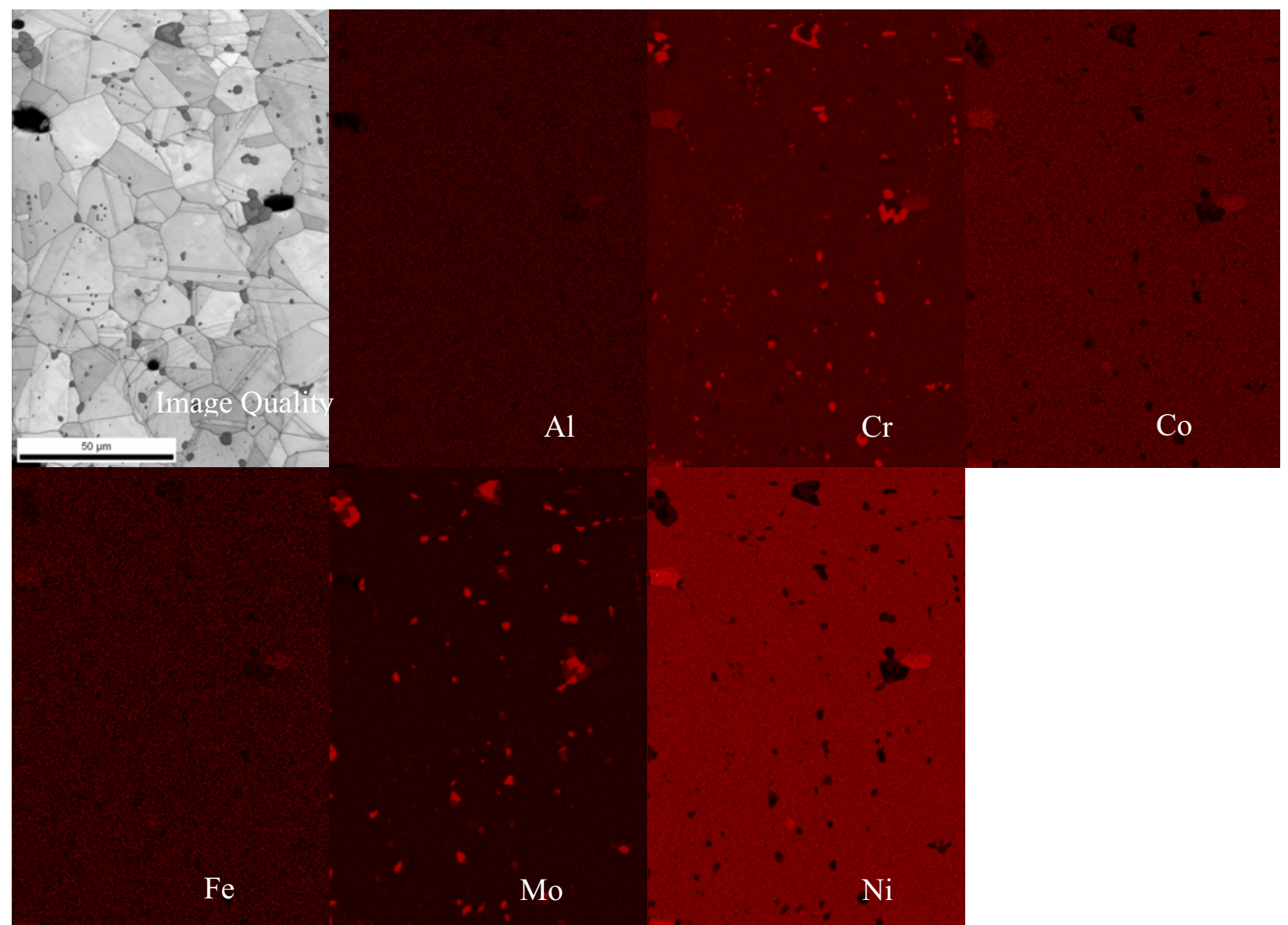

Figure 20. Images of the same area generated from image quality and EDS information gathered during OIM scans.

As mentioned above, there appears to be grain size banding - bands of small grains alternating with bands of large grains. Figure 21 shows the difference along with a plot of the grain size distributions for each area. The grain size is approximately twice as large in the large grain size areas compared to the small grain size areas. Twins were included in the grain size statistics. EBSD Analytical indicated that in some samples the grain size banding was not as evident.

Preliminary analysis indicates that the preferential precipitation on grain boundaries in tension appears to be more evident in the large grain sized areas, see for example the image quality images in Figure 21 (where the tensile axis is vertical with respect to the image). However, a thorough analysis of each area is still needed to definitively make this conclusion. It appears that precipitates do not occur on any twin boundaries. Furthermore, it also appears that precipitates do not appear on any Coincidence Site Lattice (CSL) boundary (up to 545 ) and they appear to be limited to random, high angle boundaries (35$50^{\circ}$ misorientation). Preferential carbide redistribution to a particular type of boundary is not unexpected; ${ }^{41}$ however, the details are still being determined. This study for Inconel 617 and the recently initiated study of Haynes 230 will be extended in FY 2007. 

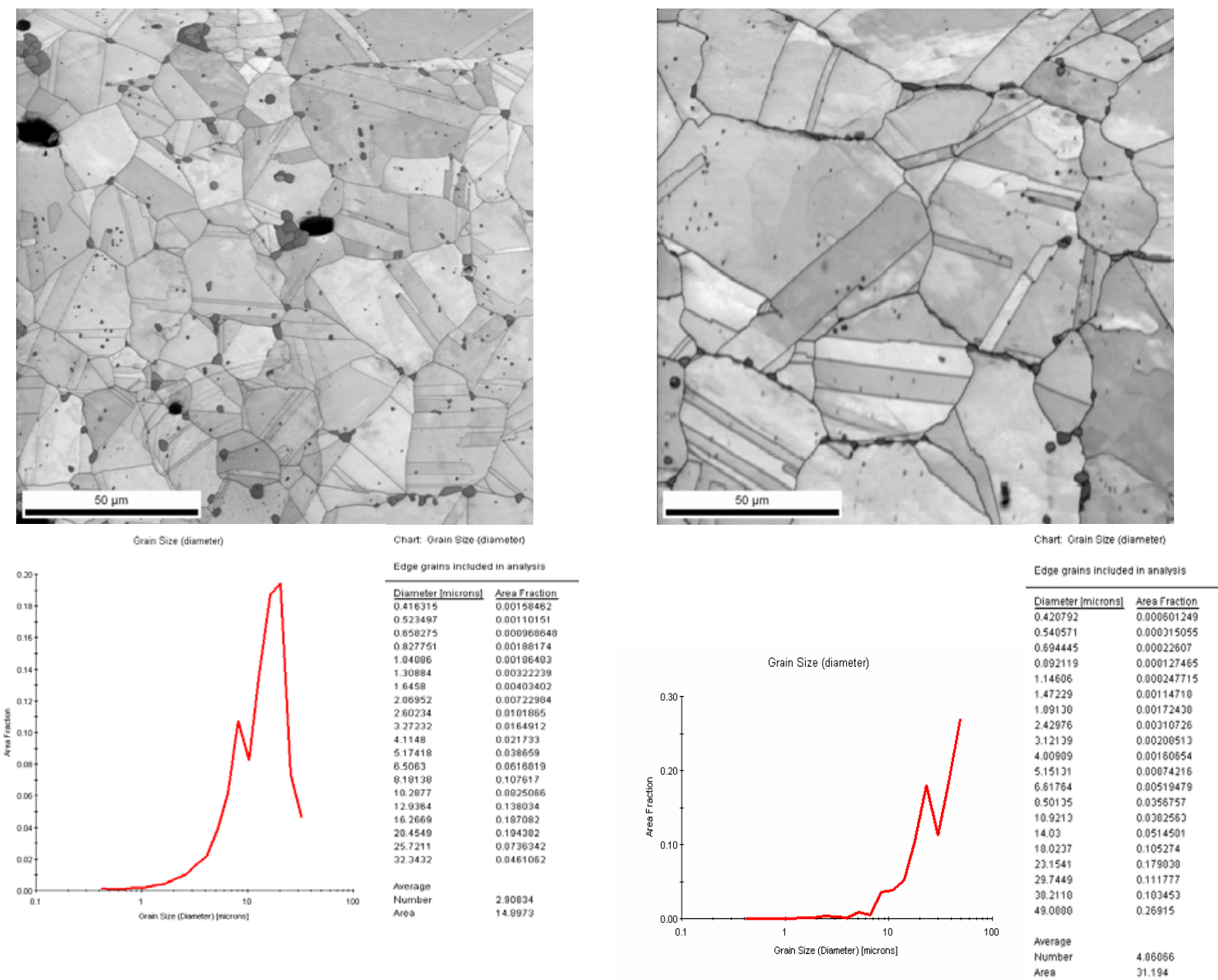

Figure 21. Images of TML-IN617-01 from areas of small grain size (left column) and large grain size (right column).

\section{Conclusions}

Three controlled impurity chemistry low velocity helium test loops have been completed and their performance characterized. Behavior or Inconel 617 and Haynes 230 with varying impurity ratios will be characterized at temperatures up to $1000^{\circ} \mathrm{C}$. The observed behavior, for example whether carburization or oxidation occurs, will be used to validate a kinetic equilibrium model. Values for kinetic constants will be determined in these experiments where none are currently available.

Furnace aging Inconel 617 in air results in formation of an adherent oxide scale and a carbide depleted zone beneath the oxide. There is some grain growth with increasing time at elevated temperature and the distribution of grain sizes becomes broader. There are modest changes in the mechanical properties for the aging conditions that have been examined. Decreased yield strength with increasing time at elevated temperature is consistent with the increasing grain size. Aging under load results in notable redistribution of carbides to some of the grain boundaries that experience tensile loading for some temperatures and applied stress values. Details of this phenomenon are being examined in detail. 


\section{References}

1. R. D. Burnette and N. L. Baldwin, 1980, "Primary Coolant Chemistry of the Peach Bottom and Fort St. Vrain High Temperature Gas-Cooled Reactors," Specialists Meeting on Coolant Chemistry, Plate-out and Decontamination in Gas Cooled Reactors, Juelich, Germany, December 1980, IAEA, Vienna, IWGGCR-2, pp. 132-137.

2. R. A. Simon and P. D. Capp, 2002, "Operating Experience with the Dragon High Temperature Reactor Experiment," Proceedings on High Temperature Reactors, Petten, Netherlands, April 2002, IAEA, Vienna, HTR-2002. pp. 1-6.

3. E. N. Shaw, 1983, History of the Dragon Project - Europe's Nuclear Power Experiment, Pergamon Press.

4. R. Baumer and I. Kalwowski, 1991, “THTR Commissioning and Operating Experience,” Energy, Vol. 16, pp. 59-70.

5. H. L. Brey, 1991, “Fort St. Vrain Operations and Future,” Energy, Vol. 16 pp. 47-58.

6. C. H. Fuller, 1989, "Fort Saint Vrain Operational Experience.” Design Requirements, Operation and Maintenance of Gas-Cooled Reactors, San Diego, CA, International Atomic Energy Agency.

7. B. Bäumer, H. Barnet, et al., eds. 1990, AVR - Experimental High-Temperature Reactor; 21 Years of Successful Operation for a Future Energy Technology, Düsseldorf, Germany, Association of German Engineers (VDI), The Society for Energy Technologies.

8. H. Nickel, T. Kondo, et al., 1984, "Status of Metallic Materials Development for Application in Advanced High-Temperature Gas-Cooled Reactors," Nuclear Technology, Vol. 66, pp. 12-22.

9. Nickel, F. Schubert, et al., 1984, "Evaluation of Alloys for Advanced High-Temperature Reactor Systems," Nuclear Engineering and Design, Vol. 78, pp. 251-265.

10. Bodmann, H. Diehl, et al., 1988, "Service Conditions and Relevant Properties of HTGR Metallic Materials," High Temperature Metallic Materials for Gas-cooled Reactors., Krakow, Poland, International Atomic Energy Agency, Vienna, Austria, pp. 15-27.

11. H. Nickel, F. Schubert, et al., 1990, "Development and Qualification of Materials for Structural Components for the High-Temperature Gas-Cooled Reactor," Nuclear Engineering and Design, Vol. 121, pp. 183-192..

12. H. Nickel, E. Bodmann, et al., 1991, "The Materials Program for the HTR in the FRG: Integrity Concept, Status of the Development of High Temperature Materials and Design Codes," Energy, Vol. 16(1/2), pp. 221-242.

13. K. Natesan, A. Purohit, et al., 2003, Materials Behavior in HTGR Environments, ANL-02/37, February, 2003.

14. R. Tanaka and T. Kondo, 1984, "Research and Development on Heat-Resistant Alloys for Nuclear Process Heating in Japan," Materials Technology, Vol. 66, pp. 76-87.

15. Special Metals Product Bulletin Inconel Alloy 617, Huntington, WV, 2005. 
16. Special Metals Product Bulletin Alloy 230, Huntington, WV, 2005.

17. Special Metals Product Bulletin Alloy 800H, Huntington, WV, 2005.

18. R. Nieder and W. Stroter, 1988, "Long-term Behavior of Impurities in an HTR Primary Circuit," VGB Kraftwerstechnik, Vol. 68, July 1988, pp. 671-676.

19. R. Nieder, 1980, "Prediction on an HTR Coolant Composition After Operational Experience with Experimental Reactors," Specialists Meeting on Coolant Chemistry, Plate-out and Decontamination in Gas Cooled Reactors, Juelich, FRG, December 1980, IAEA, Vienna, IWGGCR-2, pp. 144-152.

20. H. G. A. Bates, 1984, "The Corrosion Behavior of High-Temperature Alloys During Exposure for Times up to $10,000 \mathrm{H}$ in Prototype Nuclear Process Helium at 700 to $900^{\circ} \mathrm{C}$," Nuclear Technology 66: 415-428.

21. J. Fujioka, N. Fukasaka, et al, 1984, "Mechanical Properties of Heat-Resistant Alloys Exposed to Air and HTGR Helium at High Temperatures,” Nuclear Technology 66: 175-184.

22. H. Inouye, 1984. "Relationship of $\mathrm{H}_{2} \mathrm{O}$ and $\mathrm{CH}_{4}$ Supply Rates in HTGR Helium to the Carburization of Hastelloy-X and Alloy 800h," Nuclear Technology 66: 392-403.

23. W. J. Quadakkers and H. Schuster, 1985, "Corrosion of High Temperature Alloys in the Primary Circuit Helium of High Temperature Gas Cooled Reactors. - Part I: Theoretical Background," Werkstoffe und Korrosion, Vol. 36, pp.141-150.

24. W. J. Quadakkers, 1985, "Corrosion of High Temperature Alloys in the Primary Circuit Helium of High Temperature Gas Cooled Reactors. Part II: Experimental Results," Werkstoffe und Korrosion, Vol. 36, pp. 335-347.

25. H. J. Christ, D. Schwanke, Th. Uihlein, and H. G. Sockel, 1988, "Mechanisms of HighTemperature Corrosion in Helium Containing Small Amounts of Impurities. I. Theoretical and Experimental Characterization of the Gas Phase," Oxidation of Metals, Vol. 30, pp. 1-26.

26. H. J. Christ, U. Kunecke, K. Meyer, and H. G. Sockel, 1988, "Mechanisms of High-Temperature Corrosion in Helium Containing Small Amounts of Impurities. II. Corrosion of Nickel- Base Alloy Inconel 617," Oxidation of Metals, Vol. 30, pp. 27-51.

27. W. J. Quadakkers and H. Schuster, 1988, "Corrosion Behaviour of High Temperature Alloys in the Cooling Gas of High Temperature Reactors," High Temperature Metallic Materials for GasCooled Reactors, Cracow, Poland, International Atomic Energy Agency, Vienna, Austria.

28. H. J. Christ, U. Kunecke, K. Meyer, and H. G. Sockel, 1987, "High Temperature Corrosion of the Nickel-Based Alloy Inconel 617 in Helium containing Small Amounts of Impurities," Materials Science and Engineering, Vol. 87, pp. 161-168.

29. L. W. Graham, 1977, "Corrosion of Metallic Materials in HTR-Helium Environments," Journal of Nuclear Materials, Vol. 171, pp. 155-178. 
30. K. G. E. Brenner, and L. W. Graham, 1984, "The Development and Application of a Unified Corrosion Model for High-Temperature Gas-Cooled Reactor Systems," Nuclear Technology, Vol. 66, pp. 404-414.

31. C. S. Giggins and F. S. Pettit, 1980, "Corrosion of Metals and Alloys in Mixed Gas Environments at Elevated Temperatures," Oxidation of Metals, Vol. 14, pp. 363-413.

32. A. Roine, Outokumpu HSC Chemistry for Windows, version 5.1, Outokumpu Research Oy.

33. H. J. Grabke and G. Horz, 1977, "Kinetics and Mechanisms of Gas-Metal Reactions," Annual Review of Materials Science, Vol. 7, pp. 155-178.

34. C. Cabet, A. Terlain, P. Lett, L. Guetaz, and J. M. Gentzbittel, 2006, "High Temperature Corrosion of Structural Materials Under Gas-Cooled Reactor Helium," to be published in Materials and Corrosion, Vol. 57.

35. C. Cabet, A. Mannier, and A. Terlain, 2004, "Corrosion of High Temperature Alloys in the Coolant Helium of a Gas Cooled Reactor," Materials Science Forum, Vols. 461-464, pp. 1165-1172.

36. D. Kaczorowski and P. Combrade, May 2005, "Corrosion in Impure VHTR Helium: The Framatome Corrosion Loop," to be published in Proceedings $13^{\text {th }}$ International Conference on Nuclear Engineering, Beijing, ICONE 13-50634.

37. H. J. Christ, D. Schwanke, T. Uihlein, and H. G. Sockel, 1986, "Quantitative mass spectrometer analysis of very low impurity concentrations in gases," Journal of Physics E, Vol. 19, pp. 793-798.

38. W. Ren, T. C. Totemeier, M. Santella, R. Battiste and D. E. Clark, 2006, "Status of Testing and Characterization of CMS Alloy 617 and Alloy 230", ORNL/TM-2006-547.

39. D. F. Wilson, W. Ren, T. E. McGreevy, R. N. Wright and T. C. Totemeier, 2005, "Aging and Environmental Test Plan", ORNL/TM-2005-523.

40. R. W. Swindeman and W. Ren, 2005, “A Review of Aging Effects in Alloy 617”, ORNL/TM-2005511 .

41. S. Kihara, J. B. Newkirk, A. Ohtomo and Y. Saiga, 1980, "Morphological Changes of Carbides During Creep and Their Effects on the Creep Properties of Inconel 617 at $1000^{\circ} \mathrm{C}$ ", Metallurgical Transactions A, Vol. 11A, pp. 1019-1031.

42. S. Yang, U. Krupp, H. J. Christ and V. B. Trindade, 2005, "The Relationship Between Grain Boundary Character and the Intergranular Oxide Distribution in Inconel 718 Superalloy", Advanced Engineering Materials, Vol 7, pp. 723-726. 